\title{
Human Antigen D (HuD) Promotes Tumorigenesis And Invasion of Small Cell Lung Cancer Via Targeting IncRNA LYPLAL1-DT /miR-204-5P/Profilin 2 Axis
}

\section{Shuxin Li}

Capital Medical University

Jianyi LV

Capital Medical University

Xing Zhang

Capital Medical University

Zhihui Li

Capital Medical University

\section{Xueyun Huo}

Capital Medical University

\section{Meng Guo}

Capital Medical University

\section{Xin Liu}

Capital Medical University

\section{Ran Gao}

Chinese Academy of Medical Sciences \& Peking Union Medical College

\section{Jianan Gong}

Chinese Academy of Medical Sciences \& Peking Union Medical College

\section{Changlong Li}

Capital Medical University

\section{Weiying Li}

Beijing Chest Hospital

\section{Tongmei Zhang}

Beijing Chest Hospital

Jinghui Wang

Beijing Chest Hospital

\section{Zhenwen Chen}

Capital Medical University

Xiaoyan Du ( $\nabla$ duduyan@ccmu.edu.cn )

Capital Medical University https://orcid.org/0000-0002-4030-7299 


\section{Research}

Keywords: HuD, IncRNA LYPLAL1-DT, PFN2, Tumorigenesis, SCLC, miR-204-5p

Posted Date: September 16th, 2021

DOI: https://doi.org/10.21203/rs.3.rs-850482/v1

License: (c) (1) This work is licensed under a Creative Commons Attribution 4.0 International License. Read Full License 


\section{Abstract}

Background: Small cell lung cancer (SCLC) is one of the most malignant tumors with poor prognosis. RNA-binding protein (RBP) human antigen D (HuD) has been indicated in the process of tumorigenesis and progression of lung tumors, as well as long noncoding RNAs (IncRNA). However, the role of HuD and IncRNA in SCLC remains unknown.

Methods: Realtime PCR were used to examine the circulating levels of LYPLAL1-DT in the 46 SCLC patients and 18 normal controls. Assays of dual- luciferase reporter system, RNA pull-down were performed to determine that LYPLAL1-DT could sponge miR-204-5p to upregulate the expression of PFN2. Migration and invasion assay, CCK8 and colony formation assay were used to detect the malignant effect of HuD and LYPLAL1-DT. Tumor xenograft model was established and IHC assay was performed to determine how HuD and LAPLAL1-DT impact in vivo.

Results: We revealed that HuD was highly expressed in SCLC tissues and cell lines. HuD boosts the proliferation, migration, invasion of SCLC cells by increasing the PFN2 mRNA stability, which promotes cytoskeleton formation. HuD also enhanced the stability of IncRNA LYPLAL 1-DT, which expressed highly in the serum of patients with SCLC and acted as an oncogenic InCRNA in SCLC cells as confirmed in vitro and in vivo. Mechanistically, LYPLAL 1-DT functioned as a competing endogenous RNA (ceRNA) for sponging miR-204-5p, leading to the upregulation of its target PFN2 to promote SCLC cell proliferation and invasion. In summary, our data reveal a regulatory pathway in which HuD stabilizes PFN2 mRNA and LYPLAL 1-DT, which in turn increases PFN2 expression by binding to miR-204-5p, and ultimately promotes tumorigenesis and invasion in SCLC.

Conclusions: Our findings reveal novel regulatory axes involving HuD/PFN2 and IncRNA LYPLAL 1$D T / m i R-204-5 p / P F N 2$ in the development and progression of small cell lung cancer (SCLC), providing novel prognostic indicators and promising therapeutic targets.

\section{Background}

Small cell lung cancer (SCLC) accounts for 13\% 15\% of all lung cancers and rates the sixth most common cause of cancer-related mortality [33]. SCLC is characterized by rapid tumor growth, high vascularity, genomic instability, and early metastatic dissemination [23]. Over the last 30 years there has been a distinct paucity of significant breakthrough in SCLC therapy. The patient's survival level stays at $20 \%$ in the limited period and $2 \%$ in the extensive period [19]. Hence, we need to explore the intensive molecular mechanism involved in SCLC and identify novel molecular biomarkers and to unveil the mechanistic panoramic of SCLC.

RNA-binding protein (RBP) human antigen $\mathrm{D}(\mathrm{HuD})$, also known as embryonic lethal, abnormal vision like 4 (ELAVL4), is mainly expressed in differentiated neurons. Multiple studies have demonstrated that HuD controls neuronal commitment, plasticity and axonal growth [17]. It was revealed that apoptosis, differentiation of neurons and development of nervous system increased in HuD knockout (-/-) mice [1, 
17]. As an RNA-binding protein, HuD carries three RNA recognition motif (RRM) domains and binds to the AU-rich region of mRNA 3'-UTR, implicating its role in the regulation of mRNA stability, alternative splicing, alternative polyadenylation, RNA localization, and translation [16]. The association between HuD and SCLC was first mentioned in 1994 that HuD is positively expressed in SCLC tissues and 18 SCLC cell lines but nearly undetectable in normal lung tissues [32]. Subsequently, it was reported that DNA vaccination against HuD antigen suppressed HuD-expressing tumor growth in a murine SCLC model [26]. Graus F et.al showed that the presence of Hu-Ab in the patients of SCLC is a strong and independent predictor of complete response to treatment [12]. More recently research showed approximately $10 \%$ of SCLC develop a paraneoplastic syndrome (PNS) due to a detectable serum autoantibody [16]. Our previous study showed that HuD antigen could act as a potential diagnostic criterium for SCLC [36]. All above evidences implicate that HuD may be a pivotal factor in SCLC. Unfortunately, the underlying mechanism of HuD pertained to the tumorigenesis and progression of SCLC has not seen any breakthrough over past 10 years.

Long noncoding RNAs (IncRNA) are a class of RNA molecules consisting of more than 200 nucleotides without protein-coding potential. Accumulating evidences indicate that IncRNAs constitute a regulatory system that functions at the transcriptional and posttranscriptional levels [13]. LncRNAs are involved in various biological processes, such as cell proliferation, differentiation, and metastasis [25]. Dysregulation of IncRNA has implication in the occurrence and development of tumors [15]. However, only a fraction of the IncRNAs in the genome have been deciphered and yet their functions in tumorigenesis, especially in SCLC, remains largely unknown [20]. Profound insight into the IncRNA-dependent gene-regulatory mechanisms will provide useful prognostic biomarkers and allow opportunity of developing precise therapy for SCLC. We recently screened IncRNA by RNA-sequencing and found IncRNA LYPLAL1-DT could protect endothelial cell from high glucose and inflammatory injury (data not published). However, the role of LYPLAL1-DT in high vascularity characterized SCLC is absolutely unknown.

Profilin is a small actin-binding protein $(12-17 \mathrm{kDa})$ that promotes actin polymerization [21]. In mammals, four profilin isoforms have been reported (profilin1-4). Profilin2 (PFN2) is tissue-specific and mainly expressed in the brain whereas profilin1 is universally present in all cell types and tissues [39]. Deletion of PFN2 led to increased neurotransmitter exocytosis and novel-seeking behavior in mice [28]. The neural cell adhesion molecule (NCAM) controls the proliferation and differentiation of neural progenitor cells by interacting with PFN2 [14]. A growing number of studies show that PFN2 is involved in the process of tumorigenesis. Kim et al. showed that PFN2 promoted migration, invasion and stemness of human colorectal cancer cells [18]. In non-small cell lung cancer, inhibition of PFN2 by miRNA-30a-5p can suppress epithelial-mesenchymal transition [40]. We previously reported that PFN2 is highly expressed in SCLC and could improve tumor growth and metastasis via exosome and angiogenesis [2]. Consequently, we have been curious about the mechanism of high expression of PFN2 in SCLC.

In the current study, we found that HuD could increase tumor growth and invasion by stabilizing PFN2 mRNA and a new IncRNA LYPLAL1-DT, the biological function of which has not yet been clarified in tumorigenesis. As a competing endogenous RNA (ceRNA), LYPLAL 1-DT sponges miR-204-5p to increase 
PFN2 expression, which boosts the malignant phenotype of SCLC. Our work elucidates HuD/LYPLAL1DT/miR-204-5p/PFN2 axis in the tumorigenesis and progression of SCLC and provides prognostic indicators as well as a promising therapeutic target for SCLC patients.

\section{Results}

\section{HuD contributes to migration, invasion and cell proliferation of SCLC in vitro and in vivo}

Studies have shown that HuD is 100\% expressed in SCLC [7]. We detected the expression of HuD on 6 SCLC tissues and 5 normal lung tissues with immunohistochemical analysis. Data showed that the expression of HuD increased significantly in the SCLC tissues (6/6) compared with normal tissues (0/5) (Fig. 1A). To investigate the role of HuD in SCLC, we constructed stable HuD-overexpression (HuD-OE) and HuD-knockdown (HuD-KD) SCLC cell lines via lentivirus infection (Supplementary Fig. S1A and S1B). Transwell assay revealed that the migration and invasion ability were significantly increased in HuD-OE cells and decreased in HuD-KD cells (Fig. 1B, C). RTCA showed that HuD overexpression could increase the proliferation of $\mathrm{H} 446$ cells whereas HuD knockdown had the opposite effect (Fig. 1D and E). We also found that overexpression of HuD boosted a significant increasement in colony formation (Fig. 1F). The mice xenograft tumor model showed that HuD-OE significantly promoted tumor growth (Fig. 1G). Ki67 immunostaining showed that the fluorescence intensity and Ki67-positive cells were both much higher in HuD-OE group (Fig. $1 \mathrm{H}, 1 \mathrm{I}$ and $1 \mathrm{~J}$ ). These findings demonstrate that HuD initiates the growth and invasion of SCLC cancer cells.

\section{HuD augments migration and invasion of SCLC by upregulating PFN2 expression}

In eukaryotic cells, actin dynamics plays a critical role in cell invasion and morphological changes [29]. To determine whether HuD is able to mediate the regulation of actin dynamics, the soluble fraction (cytoplasm) and insoluble fraction (membrane and cytoskeleton) were isolated from HuD-OE and HuD$\mathrm{OC}$ cells and the lamellipodia formation was detected. After scratching for $12 \mathrm{~h}$, cell lamellipodia toward nude area were prominent in migrating HuD-OE cells while it was unobvious in control cells (Fig. 2A). Statistical analysis also demonstrated cell numbers with lamellipodia were significantly increased in HuD-OE cells (Fig. 2B). Furthermore, F-actin, which is present mainly in insoluble fractions, was much higher in HuD-OE cells than in HuD-OC cells; whereas G-actin, which exists mostly in soluble fractions, was similar (Fig. 2C).

Profilins are well-known actin-binding proteins and regulate the dynamics of actin, thereby playing a key role in vivo cell motility [9]. In the current study, we found that HuD promote PFN2 but not PFN1 expression in SCLC cell (Fig. 2D). Notably, by analyzing the dataset provide by George $\mathrm{J}$ et al., we found PFN2 expression exhibited a positive correlation with HuD expression in SCLC clinical samples $(R=$ 0.315) [11]. We suspected that HuD may promote migration and invasion of SCLC through upregulating PFN2, then confirmed by small interference RNAs targeting PFN2 (siPFN2). We showed that the migration and invasion of HuD-OE cells were reduced markedly when cell were transfected with siPFN2 (Fig. 2E and 2F). Furthermore, transient transfection of PFN2-OE plasmid into HuD-KD cells reversed the decreasing 
trend of migration and invasion of the cells (Fig. $2 \mathrm{G}$ and $2 \mathrm{H}$ ). These data collectively indicate that HuD exerts its effect via upregulating PFN2. Furthermore, we transplanted HuD-OC cells or HuD-OE cells into SCID-NOD mice. IHC assay and western blot assay showed that PFN2 significantly increased in HuD-OE group (Fig. 2l and 2J).

\section{HuD promotes the stability of PFN2 mRNA by binding to its $3^{\prime}$-UTR}

HuD could directly and specifically enhance the translation efficiency of mRNAs known to be involved in motor neuron differentiation and axonogenesis [35]. RIP assay was performed to demonstrated that HuD directly bound to the PFN2 mRNA (Fig. 3A). Additionally, when de novo synthesis of mRNA was blocked with actinomycin D, the decay rate of PFN2 was much slower in HuD-OE SCLC cells than in control cells (Fig. 3B). To clarify the binding site of HuD, we cloned the whole 3'UTR region and the fragments (S1, S2, S3) of PFN2 mRNA (Fig. 3C and 3D). Luciferase reporter analysis showed that HuD overexpression significantly increased the luciferase activity of whole PFN2 3'-UTR and PFN2 S3, while PFN2 S1 and PFN2 S2 activities exhibited slightly change (Fig. 3E). Our results demonstrated that HuD could increase PFN2 mRNA stability and expression by directly binding to the distal part of 3'-UTR.

\section{HuD stabilized IncRNA LYPLAL1-DT, which enhances the proliferation, migration and invasion of SCLC cells}

Deregulation of IncRNA plays a vital role in the occurrence and development of tumors, including small cell lung cancer [22,44]. Most of IncRNAs requires the interaction with one or more RNA-binding proteins [6]. Our previous studies indicated that IncRNA LYPLAL1-DT was closely correlated with vascular endothelial cells migration and invasion (data not published). Data from the bioinformation service website (http://pridb.gdcb.iastate.edu/RPISeq) showed that LYPLAL1-DT contained multiple AU-rich regions and most probably bound to HuD ( $R F=0.9)$ (Fig. S2). RT-PCR analysis demonstrated that the expression level of LYPLAL1-DT was aligned with the HuD expression (Fig. 4A and 4B). Meanwhile, HuD overexpression increased the translocation of LYPLAL1-DT from nucleus to cytoplasm (Fig. 4C). To investigate the biological significance of HuD binding to LYPLAL1-DT, we first examined LYPLAL1-DT stability when HuD overexpressed. With actinomycin D treatment, HuD remarkably slowed down the LYPLAL1-DT decay rate (Fig. 4D and 4E). Ribonucleoprotein immunoprecipitation (RIP) analysis demonstrated that LYPLAL1-DT was highly enriched (>8-fold) in HuD IP samples relative to IgG samples (Fig. 4F), revealing that HuD selectively associates with LYPLAL1-DT. Additionally, in the xenograft tumor mice model, LYPLAL1-DT significantly increased in HuD-OE group (Fig. 4G).

With these in vitro findings, we went on to determine the circulating levels of LYPLAL1-DT in the patients based on a collection of 46 serum samples from SCLC patients and 18 normal controls. We found that the level of LYPLAL1-DT was significantly higher in the SCLC group (Fig. 4H). To verify the effects of LYPLAL1-DT on growth, migration and invasion of SCLC, we first detected the expression level in two common SCLC cell lines of H446 and H69, found that LYPLAL1-DT expressed higher in H69 than in H446 (Fig. S3A). Then we developed a stably LYPLAL1-DT-overexpressing H446 cell line (Fig. 4I). CCK-8 assay showed that LYPLAL1-DT overexpression significantly increased the proliferation of H446 cells. However, 
knockdown of LYPLAL1-DT in H69 cell (Fig.S3C) significantly lowered the ability of proliferation of SCLC cell (Fig. 4J). Moreover, migration and invasion capacity were accessed by transwell, and wound-healing assay. The results revealed that LYPLAL1-DT overexpression dramatically boosted these malignant phenotypes (Fig. 4K, 4L and Fig.S3B).

\section{LYPLAL1-DT acts as a competitive endogenous RNA with miR-204-5p to upregulate PFN2 expression}

Recently, an increasing amount of evidence has demonstrated that IncRNAs function as ceRNA to sequester miRNAs, which decreases miRNA targets at the level of posttranscription regulation [41]. To determine whether LYPLAL1-DT works as a ceRNA, miRNAs potentially bound to it were predicted using the program of miRcode (mircode.org) and Starbase (http://starbase.sysu.edu.cn/). Among 4 potential miRNAs with high scores, miR-204-5p is the most significantly downregulated one in LYPLAL1-DT-OE cells (Fig. 5C, Fig. S4). Intriguingly, PFN2 is one of candidate regulatory targets miR-204-5p harbors (Fig. $5 A$ ), and the level of miR-204-5p decreased in the serum of SCLC patients compared with healthy volunteers (Fig. 5B). Consistently, the expression level of miR-204-5p was significantly reduced in LYPLAL1-DT-OE cells compared with LYPLAL1-DT-OC cells (Fig. 5C). We detected higher expression of PFN2 in the serum of SCLC patients and in LYPLAL1-DT-OE cells than their normal controls, respectively (Fig. 5D and 5E). Nevertheless, miR-204-5p mimic transfection reversed the increased PFN2 expression in LYPLAL1-DT-OE cells (Fig. 5F). Furthermore, luciferase reporter assay showed that the luciferase activity of wild type LYPLAL1-DT or PFN2 was decreased by miR-204-5p mimics, while mutant LYPLAL1-DT or PFN2 showed no significant response (Fig. $5 \mathrm{G}$ and $5 \mathrm{H}$ ). The proliferation ability enhanced by LYPLAL1DT overexpression could also reduce by either siPFN2 or miR-204-5p mimic transfection (Fig. $5 \mathrm{I}$ and 5J). Further RIP assay indicated that LYPLAL1-DT and PFN2 could bind with the RISC formed by miR-204-5p and Ago2 (Fig. 5K). However, when knocking down LYPLAL1-DT in HuD-OE cells, we found the expression level of PFN2 was remarkably reduced, similar to HuD-OC + LYPLAL1-DT-OC cells (Fig. 5L and 5M), which highlighted the key effect of LYPLAL1-DT in HuD-regulatory pathway. Collectively, our data verified that LYPLAL1-DT sponged miR-204-5p to upregulate PFN2 expression.

\section{LYPLAL-DT promotes tumorigenesis and invasion of SCLC via miR-204-5p/PFN2 axis in vivo}

To clarify the oncogenic function of LYPLAL1-DT in vivo, LYPLAL1-DT-OE cells and control cells were implanted subcutaneously into NOD/SCID mice. LYPLAL1-DT overexpression promote the formation of tumors in vivo with a significantly increase in both tumor size and weight (Fig. 6A). Ki67 staining shown that the proliferation of LYPLAL1-DT-OE cells was higher than controls (Fig. 6B and 6C). To further define the LYPLAL-DT/miR-204-5p/PFN2 axis, we evaluated the expression levels of miR-204-5p and PFN2 in mice xenograft tumor tissues. As shown in Fig. 6D, 6E and 6F, miR-204-5p was reduced sharply while PFN2 upregulated remarkably. Immunohistochemical staining manifested that PFN2 levels were increased in LYPLAL1-DT-OE group than the controls (Fig. 6G).

Taken together, we propose that HuD/ LYPLAL1-DT/ miR-204-5p/PFN2 axis induces proliferation, migration, invasion of SCLC. HuD stabilizes PFN2 and LYPLAL1-DT RNAs. LYPLAL1-DT, functions as a ceRNA by binding to miR-204-5p, promotes the expression the PFN2 and exerts its function (Fig. $6 \mathrm{H}$ ). 


\section{Discussion}

As one of the most malignant tumors, SCLC treatment faces big challenge due to its predisposition for early dissemination, quickly development and early metastasis, even lack of efficient therapeutic target [31]. Many studies have shown that SCLC express high-levels of HuD protein [4, 38]. Some data demonstrated that alternation of Hu genes might be involved in the tumorigenesis and/or progression of neuroendocrine lung tumors [5]. Sasahira T et al. found that HuD was observed in $36.6 \%$ of oral squamous cell carcinoma and significantly associated with histological differentiation, nodal metastasis and mode of invasion, suggesting that HuD may play some role in tumor invasion or metastasis [30]. Ectopic overexpression of HuD inhibits MYCNRNA decay, thereby contributes to the malignant phenotype of neuroblastoma cells [24]. In this study, we first revealed HuD promoted cellular proliferation, migration, and invasion, which indicating its oncogenic character. Further test discovered that HuD induced filamentous actin (F-actin) reorganization, which provided an essential condition for SCLC migration and invasion, for altering the dynamics of F-actin/G-actin turnover is a key step for cell migration and invasion. HuD belongs to an RNA binding protein family, ELAV-like family. ELAV-like proteins contain three ribonucleoprotein-2/ribonucleotide-1 ribonucleotide recognition motifs. By binding to both AU-rich element and the poly $(A)$ tail, they are able to affect the processing of transcripts, alternative splicing, etc. [24]. Study have shown that HuR (ELAVL1) participates in the export of target mRNA to the cytoplasmic compartment, thus protecting them from degradation. Compared with other family members, HuD is highlighted its function in neural system. Studies showed that in vivo knockdown of HuD impaired learning performance and especially inhibited up-regulation of GAP-43 mRNA involved in synaptic plasticity remodeling [27]. HuD promotes neuronal differentiation of neural stem/progenitor cells (NSCs) in the adult subventricular zone by stabilizing special adenine-thymine (AT)-rich DNA-binding protein 1 mRNA [37]. Moreover, HuD can interact with circRNAs and regulate their expression and transport, which could control neuronal differentiation and synaptic plasticity [8]. Here, we defined firstly that HuD could binding PFN2 distal part of 3'-UTR, then predicted and further confirm HuD stabilize AU-rich element of IncRNA LYPLAL1-DT. These data newly expanded and enrich the role of HuD as an RNA binding protein.

Although dozens of literatures have shown that IncRNAs play pivotal roles in tumorigenesis, the researches in SCLC are pretty limits. In the current study, we firstly found an absolutely new IncRNA LYPLAL1-DT which expressed highly in SCLC patient serum, could promote tumor growth and migration with gain- loss- of function by in vivo and in vitro test, strongly confirmed that LYPLAL1-DT would be a critical factor in SCLC development. A growing body of literatures regard that IncRNAs play the ceRNA role in tumor [3]. LncRNA PVT1 has been confirmed regulating gemcitabine resistance of pancreatic cancer by miR-619-5p/Pygo2 and miR-619-5p/ATG14 pathway [45]. A famous IncRNA HOTTIP was involved in SCLC tumorigenesis by sponging miR-574-5p and affecting the expression of EZH1 [34]. In the present study, we investigate whether LYPLAL1-DT can act as a ceRNA in SCLC. Firstly, we performed bioinformatic analysis and select lower expression of miR-204-5p in LYPLAL1-DT overexpression SCLC cell. Then luciferase assays and RNA immunoprecipitation assays with the Ago2 protein revealed that LYPLAL1-DT is engaged in complementary binding with miR-204-5p. MiR-204-5p is received concern just since 2020, and about 20 references reported it to be a tumor factor that can inhibit colorectal cancer cell 
growth and chemoresistance via exosome [43], promote apoptosis and decrease migration in gastric cancer [42], suppressed oral cancer cell aggressiveness [10], etc. However, no evidence has shown it function in SCLC up to now. Our current finding identifies miR-204-5p as the sponging target of LYPLAL1DT in SCLC. Moreover, the miR-204-5p target gene PFN2 was confirmed in our previous study to activate Smad2/3 expression [2], and mediate endothelial cell migration via ERK pathway (data not published). Furthermore, we demonstrated that miR-204-5p overexpression, PFN2 depletion significantly restored changes in LYPLAL1-DT overexpression. Taken together, our results indicated that the ectopic expression of LYPLAL1-DT was sufficient to improve SCLC development as a ceRNA to regulate the miR-2045p/PFN2 axis.

Emerging evidences showed that PFN2 is involved in the cancer progression. In ovarian cancer, PFN2 is activated in stem-A subgroup through non-canonical Wnt pathway and associated with poor clinical prognosis. In non-small cell lung cancer, PFN2 is overexpressed and suppresses the recruitment of HDAC1 to Smad2/Smad3 by preventing nuclear translocation of HDAC1, which leading to EMT of cancer cells. Our study demonstrated that significantly high expression of PFN2 could promote both migration and metastasis of SCLC [2]. In this study, we primarily revealed the mechanism of elevating PFN2 in SCLC by two branches and one trigger HuD. First, HuD could bind to the AU-rich region in the 3'-UTR of PFN2 mRNA and increased its half-life. Since mRNA half-life is a parameter reflecting the mRNA decay and translational processing, we propose that HuD can regulate the expression of PFN2 at posttranscriptional level. Second, PFN2 could be upregulated by LYPLAL1-DT with sponging miR-204-5p pathway which is still initiated by HuD binding and stabilizing LYPLAL1-DT. These results clarify the relationship between HuD and PFN2 via both directly stabilizing and LYPLAL1-DT/miR-204-5p pathway.

Some limitations still exist in our study. First, LYPLAL1-DT level has been just detected in patient serum, unfortunately did not confirm in SCLC tissue. Since the number of SCLC case is limit and it is difficult to obtained fresh SCLC tissue, especially the ones simultaneously matching with the serum sample. As a fallback solution, we confirmed highly expressed- HuD and PFN2 in the current study and our previous report, respectively. Second, LYPLAL1-DT is a kind of new IncRNA, lacking information in RNA database, plus short of SCLC RNA-sequencing database, we could not analyze the relationship of LYPLAL1-DT and clinical data of SCLC, such as overall survival rate, prognosis, etc. Last, HuD, LYPLAL1-DT, miR-204-5p or PFN2, which is/are the most efficient therapeutic target has not been explored, whereas limit our data application in clinical practice. It is also still nebulous in the upstream regulation factors of HuD. For ELAV-like proteins, it seems that various signaling pathways involved in their activation, such as MAPK signaling and $\mathrm{PI} 3 \mathrm{~K}$ signaling et al. All these questions inspire us to seek up further investigation and solution in the future.

\section{Conclusion}

Our work demonstrates that HuD could promote the proliferation and migration of SCLC through two axes of the HuD/PFN2, as well as HuD/LYPLAL1-DT/miR-204-5p/PFN2. It provides tangible evidence of 
HuD function in SCLC pathogenesis, and demonstrate the upstream of PFN2 which could be developed as efficient biomarkers of therapy and prognosis for the deadly disease.

\section{Materials And Methods}

\section{Tissue specimens and serum samples}

Six SCLC tissues and five normal lung tissues were obtained from Beijing Shi Ji Tan hospital. All samples were confirmed as SCLC by pathologic examination. A paraffin-embedded tissue specimen was available for each included patient. Forty-six serum samples from SCLC patients and 18 normal controls were collected from Beijing Chest Hospital. All patients were informed consent prior to the collection of specimens according to the institutional guidelines. Under the protocol approved by the Institutional Review Board, informed consents were obtained from the patients or their guardians.

\section{Cell culture}

The lung cancer cell lines $\mathrm{NCl}-\mathrm{H} 446$ were obtained from Chinese National Infrastructure of Cell Line Resource. Cell lines were maintained in RPMI1640 supplemented with 10\% FBS (PAN). Other cell lines, including 293T, were cultured in DMEM and supplemented with 10\% FBS. All cell lines were cultured at $37^{\circ} \mathrm{C}$ with $5 \% \mathrm{CO} 2$.

\section{Lentivirus package and stably transfected cell lines construction}

The overexpression lentivirus vector of HuD (HuD-OE), the knockdown (HuD-KD), overexpression of LYPLAL1-DT and their negative controls (HuD-OC, HuD-KC, LYPLAL1-DT) were constructed. For constructing stable expressing cells, SCLC cell lines H446 were respectively infected with lentivirus vectors for $48 \mathrm{~h}$. Then, cells were selected with $2 \mu \mathrm{g} / \mathrm{ml}$ puromycin (Invivogen, Cat\#ant-pr-1) for 3 weeks. Further, realtime RT-PCR was used to examine the overexpression and knockdown efficiency of these cells.

\section{Transient transfection}

The PFN2 expression vector pLV-PFN2 and control vector were purchased from Abcam company. For the knockdown of PFN2, siRNAs or negative control siRNA (Abcam) were transfected into the cells by using Lipofectamine 3000 (Invitrogen, CA, USA, Cat\# L3000015). The miR-204-5p mimic and negative controls were purchased from HANBIO Ltd (HANBIO, Shanghai, China). They were transfected at a final concentration of 50nM via an RNAfit reagent (HANBIO, Shanghai, China), following the manufacturer's instruction.

\section{Cell proliferation assay}

The cell proliferation rate was assessed using a real-time cell analyzer (RTCA). Cells were suspended in the culture medium, 8000 cells per well of the E-plate with 4 replicates. After incubation at room 
temperature for $15 \mathrm{~min}$, the E-plate was placed onto the RTCA Station in the incubator for continuous recording. Cell index values were recorded every $15 \mathrm{~min}$ for $72 \mathrm{~h}$.

\section{Western blot analysis}

The protein samples were separated using sodium dodecylsulphate polyacrylamide gel electrophoresis and transferred onto poly(vinylidene fluoride) membranes (Millipore, Cat\#IPVH00010). The membranes were blocked with $5 \%$ skimmed milk (BD, Cat\#232100) for $1 \mathrm{~h}$ at room temperature and incubated with primary antibody overnight at $4{ }^{\circ} \mathrm{C}$. The membranes were subsequently incubated with secondary antibody for $1 \mathrm{~h}$ at room temperature. Protein signals were detected using enhanced chemiluminescence. The antibodies used in this study are listed in Table 1.

Table 1. Antibodies used in the study

\begin{tabular}{ll} 
Protein names & Manufacturer \\
\hline ELAVL4(HuD) & Proteintech, Cat\#24992-1-AP \\
\hline PFN2 & Abcam, Cat\#ab191054 \\
\hline GAPDH & CST, Cat\#5174 \\
\hline PFN1 & Abcam, Cat\#ab50667 \\
\hline Mouse IgG & Proteintech, Cat\#B900620 \\
\hline Monoclonal ANTI-FLAG & SIGMA, Cat\#F1804-50UG
\end{tabular}

\section{Quantitative PCR analysis}

Total RNA was extracted using TRIzol (Vazyme, Cat\#R401-01) and reverse transcribed using PrimeScriptTM RT Kit (Abcam, Cat\#G490). qRT-PCR was performed using EvaGreen 5×qPCR MasterMix (Abcam, Cat\# MasterMix-5S). mRNA level was quantified by the $2-\Delta \Delta C$ t algorithm with $\beta$-actin as the normalizer gene. All the primers used are found in Table 2 .

Table 2. Primer sequences for $\mathrm{qPCR}$ 


\section{$\begin{array}{lll}\text { Gene } & \text { Forward primers } & \text { Reverse primers }\end{array}$ \\ names}

\begin{tabular}{|c|c|c|}
\hline PFN2 & 5'-AGCAAGGTGCCGGTGTACA-3' & 5'-AACCATGCGCTACAAAAGGAA-3' \\
\hline \multirow[t]{2}{*}{ HuD } & $\begin{array}{l}\text { 5'- } \\
\text { CGGGATCCGAGCCTCAGGTGTCAAATG-3' }\end{array}$ & $\begin{array}{l}\text { 5'- } \\
\text { CCGCTCGAGGTCAGGACTTGTGGGCTTT }\end{array}$ \\
\hline & & GTGTG-3' \\
\hline $\begin{array}{l}\text { LYPLAL1- } \\
\text { DT }\end{array}$ & 5'-CAGCCTCGTGTGGACTTCTG-3' & 5'-CTGCAAACATCCTGTGCGAG-3' \\
\hline
\end{tabular}

miR-204-5p 5'-CGCGTTCCCTTTGTCATCCT-3'

5'-AGTGCAGGGTCCGAGGTATT-3'

\section{Migration and invasion assay}

Migration assays were performed using a transwell plate (Corning, Cat\#3422) 『invasion assay were performed using a transwell plate with matrigel (Corning, Cat\#354480). Cells at the density of $2 \times 10^{4} / 200$ $\mu \mathrm{L}$ of serum-free RPMI 1640 were added into the upper chamber, and $500 \mu \mathrm{L}$ of the complete medium was placed into the lower chamber. The cells were incubated at $37^{\circ} \mathrm{C}$ for $24 \mathrm{~h}$. Migrated cells on the bottom surface of the filter were fixed, stained with $0.1 \%$ crystal violet, and the average number of random five fields under a microscope was calculated. All assays were repeated three times.

\section{Confocal immunofluorescence}

Cells were seeded in glass bottom cell culture dishes (NEST, Cat\#801001) at $2 \times 10^{5}$ cells/well, fixed with $4 \%$ paraformaldehyde and permeabilized in $0.1 \%$ Triton X-100/PBS. Coverslips were blocked for $1 \mathrm{~h}$ by $1 \%$ BSA, washed and exposed to a 1:100 dilution of HuD antibody (Proteintech, Cat\#24992-1-AP) overnight at $4{ }^{\circ} \mathrm{C}$. Then the cells were incubated with $1 \mathrm{mg} / \mathrm{ml}$ diluted Hochest for $5 \mathrm{~min}$ at room temperature. The cells were photographed using scanning confocal microscope.

\section{Actin cytoskeleton staining}

Actin cytoskeleton staining was performed after scratching using DyLight ${ }^{\text {TM }} 594$ Phalloidin (CST, Cat\#12877) according to the manufacturer's instructions. The cells were stained with phalloidin and the nuclei were stained with Hoechst 33358. The cells were then photographed with fluorescent microscope with at least 5 random fields along the scratch lines in each culture dish were taken. The number of cells with lamellopodia was counted and the percent of cell with lamellopodia was calculated via analyzing $40 \times$ micrographs.

\section{Subcellular Isolation}

The cell fractionation assay was performed according to the manufacturer's instructions (CST, Cat\#9038). In brief, H446 cells were suspended in $0.5 \mathrm{ml}$ of cold $1 \times$ PBS, aliquoted $100 \mu \mathrm{l}$ of cell suspension for the whole cell lysate (WCL), sonicated and centrifuge for $5 \mathrm{~min}$ at $500 \mathrm{~g}$. The pellet was 
resuspended in $500 \mu \mathrm{l}$ of Membrane Isolation Buffer and centrifuged for $5 \mathrm{~min}$ at 8,000 $\mathrm{g}$. The pellet was resuspended in $250 \mu$ of Cytoskeleton/Nucleus Isolation Buffer.

\section{RNA immunoprecipitation (RIP) analysis}

RIP analysis was performed using Anti-Flag antibodies and Magna RIPTM RNA-Binding Protein Immunoprecipitation Kit (Millipore, Billerica, MA, USA, Cat\#17-700) following the manufacturer's protocol. Cell lysate was incubated with anti-HuD or Ago2 antibody (CST, USA) and IgG antibody at $4^{\circ} \mathrm{C}$ for $6 \mathrm{~h}$. A protein-RNA complex was captured and digested with $0.5 \mathrm{mg} / \mathrm{ml}$ proteinase $\mathrm{K}$ containing $0.1 \%$ sodium dodecyl sulphate (SDS) to extract RNA. The magnetic beads were repeatedly washed with RIP washing buffer to remove non-specific adsorption as much as possible. Finally, the extracted RNA was subjected to mRNA level determination using qRT-PCR.

\section{mRNA stability assay}

ActD (5 $\mu \mathrm{g} / \mathrm{ml}$, MCE, Cat\#HY-17559), inhibiting the de novo RNA synthesis, was added to HuD-OE cells or its control cells. Total RNA was extracted at the indicated time points and PFN2 or expression was evaluated by qRT-PCR assay. The mRNA decay rate was calculated by comparing to the initial mRNA level before ActD addition.

\section{Dual-luciferase reporter gene assay}

The 3'-UTR of PFN2 mRNA and the mutant were cloned and inserted into pGL3 plasmid. Dual-luciferase reporter assay was performed following the manufacturer's instruction. The full length of the $3^{\prime}$-UTR of mRNA, the first section of 3'-UTR (S1), the middle section of 3'-UTR (S2) and the last section of the 3'-UTR (S3) were cloned and inserted into the Xbal-Fsel restriction site downstream to firefly luciferase (pGL3 promoter plasmid). 239T cells were seeded on 6-well plate and co-transfected with the constructed recombinant $(2 \mu \mathrm{g} /$ well $)$ or control plasmids and Renilla luciferase reporter $(0.1 \mu \mathrm{g} /$ well $)$ or HuD overexpression plasmids. After $48 \mathrm{~h}$, luciferase and Renilla luciferase activities were separately measured using the Dual-Luciferase Reporter Assay Kit following the manufacturer's instruction (Vazyme, Cat\# DL101-01).

\section{CCK-8 and colony formation assay}

For CCK-8 assays, cells were seeded into 96 -well plates at a density of 1,000 cells/well, and $10 \mu \mathrm{L}$ of CCK8 (Vazyme, Nanjing, CHINA) was added per well in days 0 to 5 . The cells were subsequently incubated at $37^{\circ} \mathrm{C}$ for 2 hours, and the optical density was measured at $450 \mathrm{~nm}$. For the colony formation assays, 600 cells were inoculated into 6 -well plates and cultured at $37^{\circ} \mathrm{C}$ for 10 days. The colonies were the fixed with methanol and stained with crystal violet.

\section{Tumor xenograft model}


Four-week-old NOD-SCID mice (Weitonglihua Biotechnology) were raised under specific pathogen-free conditions. HuD-OC and HuD-OE-transfected cells or LYPLAL1-DT-OC and LYPLAL1-DT-OE were, respectively, injected subcutaneously into the flank region of the mice $\left(5 \times 10^{6}\right.$ cells $/ 150 \mu \mathrm{L}$ per flank, $n=$ 5). The tumor volumes were measured every 7 days after inoculation. Eight weeks after injection, the mice were sacrificed, and the tumor nodules were harvested. The tumors, lungs, liver, and kidneys were isolated from the mice for further analysis. The protocol was approved by the Committee on the Ethics of Animal Experiments of Capital Medical University.

IHC

Small cell lung cancer tissue sections were cut into $5-\mu \mathrm{m}$ sections and then analyzed by $\mathrm{IHC}$ using antibodies against HuD (1:50; CST). Brown signals in the nuclei and cytoplasm indicated positive immunostaining. Tumor tissues from xenograft mice were fixed and incubated with anti-HuD, anti-Ki-67 or anti-PFN2 antibodies overnight at $4{ }^{\circ} \mathrm{C}$, and normal goat serum was used as a negative control. $\mathrm{IHC}$ staining was visualized using the DAKO REAL EnVision Inspection System (DAKO). The fluorescence intensity and positive staining cell number were calculated.

\section{Statistical analysis}

Statistical analyses were performed using Graphpad Prism. Data were presented as mean \pm SEM, and the statistical significance was determined by Student's t-test (t-test) or two-way ANOVA as indicated in the figure legend. Sample size $(n)$ is also reported in the figure legend for each experiment, with $n$ as the number of identically treated replicates. All tests were two-tailed, and $P$ values $<0.05$ were considered statistically significant.

\section{Abbreviations}

SCLC: Small cell lung cancer; HuD: human antigen D; PFN2: profilin 2; RBP: RNA-binding protein; ceRNA: competing endogenous RNA; IncRNA: long noncoding RNA PNS: paraneoplastic syndrome; NCAM: neural cell adhesion molecule; HuD-OE: HuD-overexpression; HuD-KD: HuD-knockdown; siPFN2: small interference RNAs targeting PFN2; PFN2-OE: Profilin 2-overexpression; RIP: Ribonucleoprotein immunoprecipitation.

\section{Declarations}

\section{Supplementary information}

Supplementary information accompanies this paper as additional file: Fig. S1, S2, S3 and S4.

\section{Ethics approval and consent to participate}

The experimental protocol was established, according to the ethical guidelines of the Helsinki Declaration and was approved by the Human Ethics Committee of Capital Medical University (Permit No. 
Z2019SY031). Written informed consent was obtained from individual or guardian participants.

All experiments with SCID mice were approved by the Committee on the Ethics of Animal Experiments of Capital Medical University (Permitted No. AEEI-2019-089).

\section{Consent for publication}

Not applicable.

\section{Availability of data and materials}

All remaining data are available within the article or available from the authors upon request.

\section{Competing interests}

The authors declare no conflicts of interest.

\section{Funding}

This work was supported by National Natural Science Foundation of China (Nos. 81902332, 31772545).

\section{Authors' contributions}

Shuxin Li, Xing Zhang, Jianyi Lv and Zhihui Li performed molecular biology experiments. Shuxin Li, Jianyi Lv, and Xiaoyan Du wrote the main manuscript. Xiaoyan Du and Zhenwen Chen designed the whole project and supervised all experiments. Xueyun Huo, Meng Guo, Xin Liu analyzed part of the data. Ran Gao, Jianan Gong, and Changlong Li, provided support with experimental techniques. Jinghui Wang, Weiying $\mathrm{Li}$, and Tongmei Zhang collected the clinical samples and provided clinical techniques. All authors read and approved the final manuscript.

\section{Acknowledgements}

Not applicable.

\section{References}

1. Akamatsu W, Fujihara H, Mitsuhashi T, Yano M, Shibata S, Hayakawa Y, Okano HJ, Sakakibara S, Takano H, Takano T, Takahashi T, Noda T, Okano H. The RNA-binding protein HuD regulates neuronal cell identity and maturation. Proc Natl Acad Sci USA. 2005;102:4625-30.

2. Cao Q, Liu Y, Wu Y, Hu C, Sun L, Wang J, Li C, Guo M, Liu X, Lv J, Huo X, Yue J, Du X, Chen Z. Profilin 2 promotes growth, metastasis, and angiogenesis of small cell lung cancer through cancer-derived exosomes. Aging. 2020;12:25981-99.

3. Chan JJ, Tay Y. Noncoding RNA:RNA Regulatory Networks in Cancer, International journal of molecular sciences, 19 (2018). 
4. D'Alessandro V, Muscarella LA, Copetti M, Zelante L, Carella M, Vendemiale G. Molecular detection of neuron-specific ELAV-like-positive cells in the peripheral blood of patients with small-cell lung cancer. Cellular oncology: the official journal of the International Society for Cellular Oncology. 2008;30:2917.

5. D'Alessandro V, Muscarella LA, la Torre A, Bisceglia M, Parrella P, Scaramuzzi G, Storlazzi CT, Trombetta D, Kok K, De Cata A, Sperandeo M, Zelante L, Carella M, Vendemiale G. Molecular analysis of the HuD gene in neuroendocrine lung cancers. Lung cancer. 2010;67:69-75.

6. D'Angelo D, Arra C, Fusco A. RPSAP52 IncRNA Inhibits p21Waf1/CIP Expression by Interacting With the RNA Binding Protein HuR. Oncology research. 2020;28:191-201.

7. Dalmau J, Furneaux HM, Cordon-Cardo C, Posner JB. The expression of the Hu (paraneoplastic encephalomyelitis/sensory neuronopathy) antigen in human normal and tumor tissues. Am J Pathol. 1992;141:881-6.

8. Dell'Orco M, Oliver RJ, Perrone-Bizzozero N. HuD Binds to and Regulates Circular RNAs Derived From Neuronal Development- and Synaptic Plasticity-Associated Genes, Frontiers in genetics, 11 (2020) 790.

9. Ding Z, Bae YH, Roy P. Molecular insights on context-specific role of profilin-1 in cell migration. Cell adhesion migration. 2012;6:442-9.

10. Fang X, Tang Z, Zhang H, Quan H. Long non-coding RNA DNM30S/miR-204-5p/HIP1 axis modulates oral cancer cell viability and migration. Journal of oral pathology medicine: official publication of the International Association of Oral Pathologists the American Academy of Oral Pathology. 2020;49:865-75.

11. George J, Lim JS, Jang SJ, Cun Y, Ozretic L, Kong G, Leenders F, Lu X, Fernandez-Cuesta L, Bosco G, Muller C, Dahmen I, Jahchan NS, Park KS, Yang D, Karnezis AN, Vaka D, Torres A, Wang MS, Korbel JO, Menon R, Chun SM, Kim D, Wilkerson M, Hayes N, Engelmann D, Putzer B, Bos M, Michels S, Vlasic I, Seidel D, Pinther B, Schaub P, Becker C, Altmuller J, Yokota J, Kohno T, Iwakawa R, Tsuta K, Noguchi M, Muley T, Hoffmann H, Schnabel PA, Petersen I, Chen Y, Soltermann A, Tischler V, Choi CM, Kim YH, Massion PP, Zou Y, Jovanovic D, Kontic M, Wright GM, Russell PA, Solomon B, Koch I, Lindner M, Muscarella LA, la Torre A, Field JK, Jakopovic M, Knezevic J, Castanos-Velez E, Roz L, Pastorino U, Brustugun OT, Lund-Iversen M, Thunnissen E, Kohler J, Schuler M, Botling J, Sandelin M, Sanchez-Cespedes M, Salvesen HB, Achter V, Lang U, Bogus M, Schneider PM, Zander T, Ansen S, Hallek M, Wolf J, Vingron M, Yatabe Y, Travis WD, Nurnberg P, Reinhardt C, Perner S, Heukamp L, Buttner R, Haas SA. Nature. 2015;524:47-53. E. Brambilla, M. Peifer, J. Sage, R.K. Thomas, Comprehensive genomic profiles of small cell lung cancer.

12. Graus F, Dalmou J, Rene R, Tora M, Malats N, Verschuuren JJ, Cardenal F, Vinolas N, Garcia del Muro J, Vadell C, Mason WP, Rosell R, Posner JB, Real FX. Anti-Hu antibodies in patients with small-cell lung cancer: association with complete response to therapy and improved survival. Journal of clinical oncology: official journal of the American Society of Clinical Oncology. 1997;15:2866-72. 
13. Guttman M, Rinn JL. Modular regulatory principles of large non-coding RNAs. Nature. 2012;482:33946.

14. Huang R, Yuan DJ, Li S, Liang XS, Gao Y, Lan XY, Qin HM, Ma YF, Xu GY, Schachner M, Sytnyk V, Boltze J, Ma QH, Li S. NCAM regulates temporal specification of neural progenitor cells via profilin2 during corticogenesis, The Journal of cell biology, 219 (2020).

15. Huarte M. The emerging role of IncRNAs in cancer. Nature medicine. 2015;21:1253-61.

16. lams WT, Shiuan E, Meador CB, Roth M, Bordeaux J, Vaupel C, Boyd KL, Summitt IB, Wang LL, Schneider JT, Warner JL, Zhao Z, Lovly CM. Improved Prognosis and Increased Tumor-Infiltrating Lymphocytes in Patients Who Have SCLC With Neurologic Paraneoplastic Syndromes. Journal of thoracic oncology: official publication of the International Association for the Study of Lung Cancer. 2019;14:1970-81.

17. Inman MV, Levy S, Mock BA, Owens GC. Gene organization and chromosome location of the neuralspecific RNA binding protein Elavl4, Gene, 208 (1998) 139-145.

18. Kim MJ, Lee YS, Han GY, Lee HN, Ahn C, Kim CW. Profilin 2 promotes migration, invasion, and stemness of HT29 human colorectal cancer stem cells, Bioscience, biotechnology, and biochemistry, 79 (2015) 1438-1446.

19. Koinis F, Kotsakis A, Georgoulias V. Small cell lung cancer (SCLC): no treatment advances in recent years. Translational lung cancer research. 2016;5:39-50.

20. Kopp F, Mendell JT, Functional Classification and Experimental Dissection of Long Noncoding RNAs, Cell, 172 (2018) 393-407.

21. Krishnan K, Moens PDJ. Structure and functions of profilins. Biophysical reviews. 2009;1:71-81.

22. Liu J, Yao L, Zhang M, Jiang J, Yang M, Wang Y. Downregulation of LncRNA-XIST inhibited development of non-small cell lung cancer by activating miR-335/SOD2/ROS signal pathway mediated pyroptotic cell death. Aging. 2019;11:7830-46.

23. Liu Y, Hu X, Jiang J, Yang L, Zhou S, Liu P, Li J, Wang Y, Hao X, Shi Y. A Prospective Study of Apatinib in Patients with Extensive-Stage Small Cell Lung Cancer After Failure of Two or More Lines of Chemotherapy, The oncologist, 25 (2020) e833-e842.

24. Manohar CF, Short ML, Nguyen A, Nguyen NN, Chagnovich D, Yang Q, Cohn SL. HuD, a neuronalspecific RNA-binding protein, increases the in vivo stability of MYCN RNA. J Biol Chem. 2002;277:1967-73.

25. Mondal T, Juvvuna PK, Kirkeby A, Mitra S, Kosalai ST, Traxler L, Hertwig F, Wernig-Zorc S, Miranda C, Deland L, Volland R, Bartenhagen C, Bartsch D, Bandaru S, Engesser A, Subhash S, Martinsson T, Caren H, Akyurek LM, Kurian L, Kanduri M, Huarte M, Kogner P, Fischer M, Kanduri C, Sense-Antisense IncRNA Pair Encoded by Locus 6p22.3 Determines Neuroblastoma Susceptibility via the USP36CHD7-SOX9 Regulatory Axis, Cancer cell, 33 (2018) 417-434 e417.

26. Ohwada A, Nagaoka I, Takahashi F, Tominaga S, Fukuchi Y. DNA vaccination against HuD antigen elicits antitumor activity in a small-cell lung cancer murine model. Am J Respir Cell Mol Biol. 1999;21:37-43. 
27. Pascale A, Gusev PA, Amadio M, Dottorini T, Govoni S, Alkon DL, Quattrone A. Increase of the RNAbinding protein HuD and posttranscriptional up-regulation of the GAP-43 gene during spatial memory. Proc Natl Acad Sci USA. 2004;101:1217-22.

28. Pilo Boyl P, Di Nardo A, Mulle C, Sassoe-Pognetto M, Panzanelli P, Mele A, Kneussel M, Costantini V, Perlas E, Massimi M, Vara H, Giustetto M. W. Witke, Profilin2 contributes to synaptic vesicle exocytosis, neuronal excitability, and novelty-seeking behavior. EMBO J. 2007;26:2991-3002.

29. Rottner K, Faix J, Bogdan S, Linder S, Kerkhoff E. Actin assembly mechanisms at a glance. Journal of cell science. 2017;130:3427-35.

30. Sasahira T, Kurihara M, Yamamoto K, Ueda N, Nakashima C, Matsushima S, Bhawal UK, Kirita T, Kuniyasu $\mathrm{H}$. HuD promotes progression of oral squamous cell carcinoma. Pathobiol $\mathrm{J}$ ImmunoPathol Mol Cell Biol. 2014;81:206-14.

31. Schneider BJ, Kalemkerian GP. Personalized Therapy of Small Cell Lung Cancer, Advances in experimental medicine and biology, 890 (2016) 149-174.

32. Sekido Y, Bader SA, Carbone DP, Johnson BE, Minna JD. Molecular analysis of the HuD gene encoding a paraneoplastic encephalomyelitis antigen in human lung cancer cell lines. Cancer research. 1994;54:4988-92.

33. Sonehara K, Tateishi K, Komatsu M, Yamamoto H, Hanaoka M. Lung immune prognostic index as a prognostic factor in patients with small cell lung cancer. Thoracic cancer. 2020;11:1578-86.

34. Sun Y, Zhou Y, Bai Y, Wang Q, Bao J, Luo Y, Guo Y, Guo L. A long non-coding RNA HOTTIP expression is associated with disease progression and predicts outcome in small cell lung cancer patients. Mol Cancer. 2017;16:162.

35. Tebaldi T, Zuccotti P, Peroni D, Kohn M, Gasperini L, Potrich V, Bonazza V, Dudnakova T, Rossi A, Sanguinetti G, Conti L, Macchi P, D'Agostino V, Viero G, Tollervey D, Huttelmaier S, Quattrone A. HuD Is a Neural Translation Enhancer Acting on mTORC1-Responsive Genes and Counteracted by the Y3 Small Non-coding RNA. Molecular cell. 2018;71:256-70 e210.

36. Wang F, Lu J, Li S, Huo X, Liu X, Du X, Li C, Wang J, Chen Z. Application of Serum ELAVL4 (HuD) Antigen Assay for Small Cell Lung Cancer Diagnosis. Anticancer research. 2017;37:4515-22.

37. Wang F, Tidei JJ, Polich ED, Gao Y, Zhao H, Perrone-Bizzozero NI, Guo W, Zhao X. Positive feedback between RNA-binding protein HuD and transcription factor SATB1 promotes neurogenesis. Proc Natl Acad Sci USA. 2015;112:E4995-5004.

38. Winter SF, Sekido Y, Minna JD, Mclntire D, Johnson BE, Gazdar AF, Carbone DP. Antibodies against autologous tumor cell proteins in patients with small-cell lung cancer: association with improved survival. J Natl Cancer Inst. 1993;85:2012-8.

39. Witke W, Podtelejnikov AV, Di Nardo A, Sutherland JD, Gurniak CB, Dotti C, Mann M. In mouse brain profilin I and profilin II associate with regulators of the endocytic pathway and actin assembly. EMBO J. 1998;17:967-76.

40. Yan J, Ma C, Gao Y. MicroRNA-30a-5p suppresses epithelial-mesenchymal transition by targeting profilin-2 in high invasive non-small cell lung cancer cell lines. Oncol Rep. 2017;37:3146-54. 
41. Yang H, Liu P, Zhang J, Peng X, Lu Z, Yu S, Meng Y, Tong WM, Chen J. Long noncoding RNA MIR31HG exhibits oncogenic property in pancreatic ductal adenocarcinoma and is negatively regulated by miR-193b. Oncogene. 2016;35:3647-57.

42. Yang S, Chen B, Zhang B, Li C, Qiu Y, Yang H, Huang Z. miR2045p promotes apoptosis and inhibits migration of gastric cancer cells by targeting HER2, Molecular medicine reports, 22 (2020) 26452654.

43. Yao S, Yin Y, Jin G, Li D, Li M, Hu Y, Feng Y, Liu Y, Bian Z, Wang X, Mao Y, Zhang J, Wu Z, Huang Z. Exosome-mediated delivery of miR-204-5p inhibits tumor growth and chemoresistance. Cancer medicine. 2020;9:5989-98.

44. Zeng F, Wang Q, Wang S, Liang S, Huang W, Guo Y, Peng J, Li M, Zhu W, Guo L. Linc00173 promotes chemoresistance and progression of small cell lung cancer by sponging miR-218 to regulate Etk expression. Oncogene. 2020;39:293-307.

45. Zhou C, Yi C, Yi Y, Qin W, Yan Y, Dong X, Zhang X, Huang Y, Zhang R, Wei J, Ali DW, Michalak M, Chen $X Z$, Tang J. LncRNA PVT1 promotes gemcitabine resistance of pancreatic cancer via activating Wnt/beta-catenin and autophagy pathway through modulating the miR-619-5p/Pygo2 and miR-6195p/ATG14 axes. Mol Cancer. 2020;19:118.

\section{Figures}


A

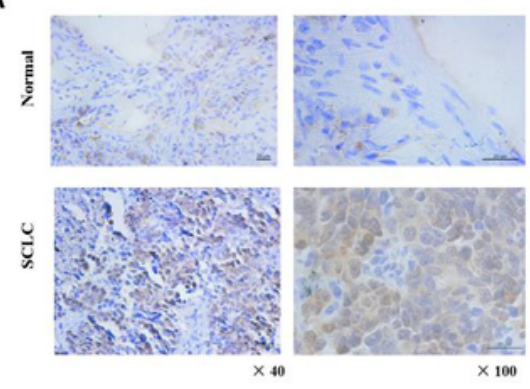

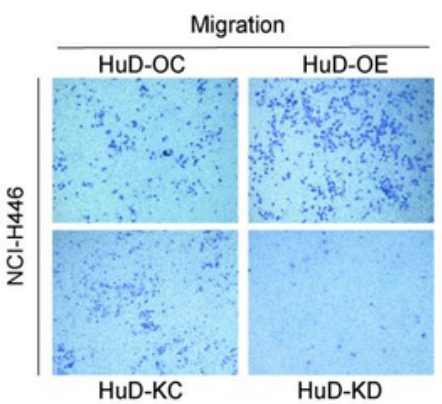

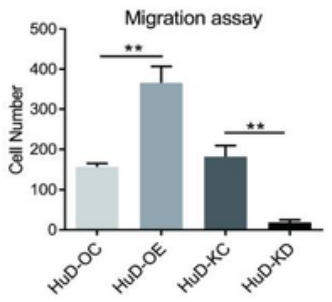

C

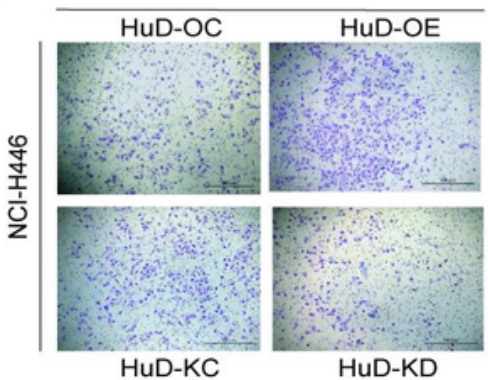

D

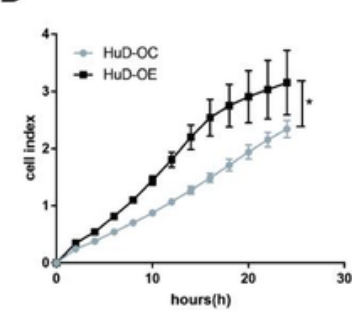

E

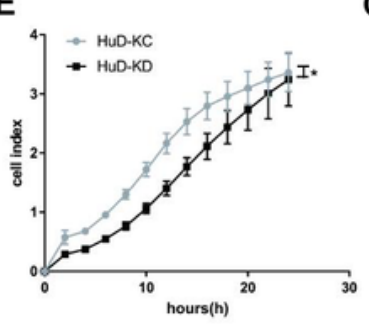

G

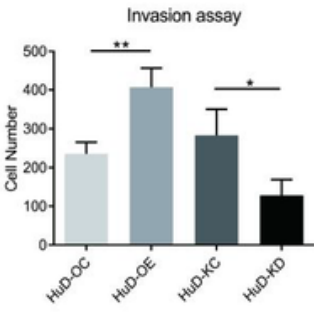

F

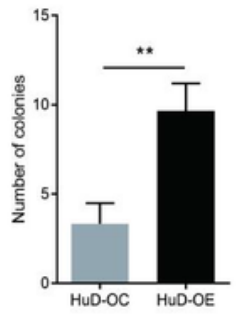

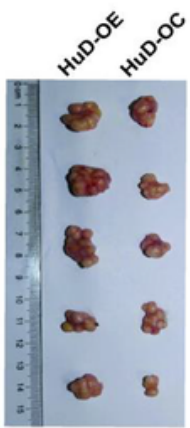
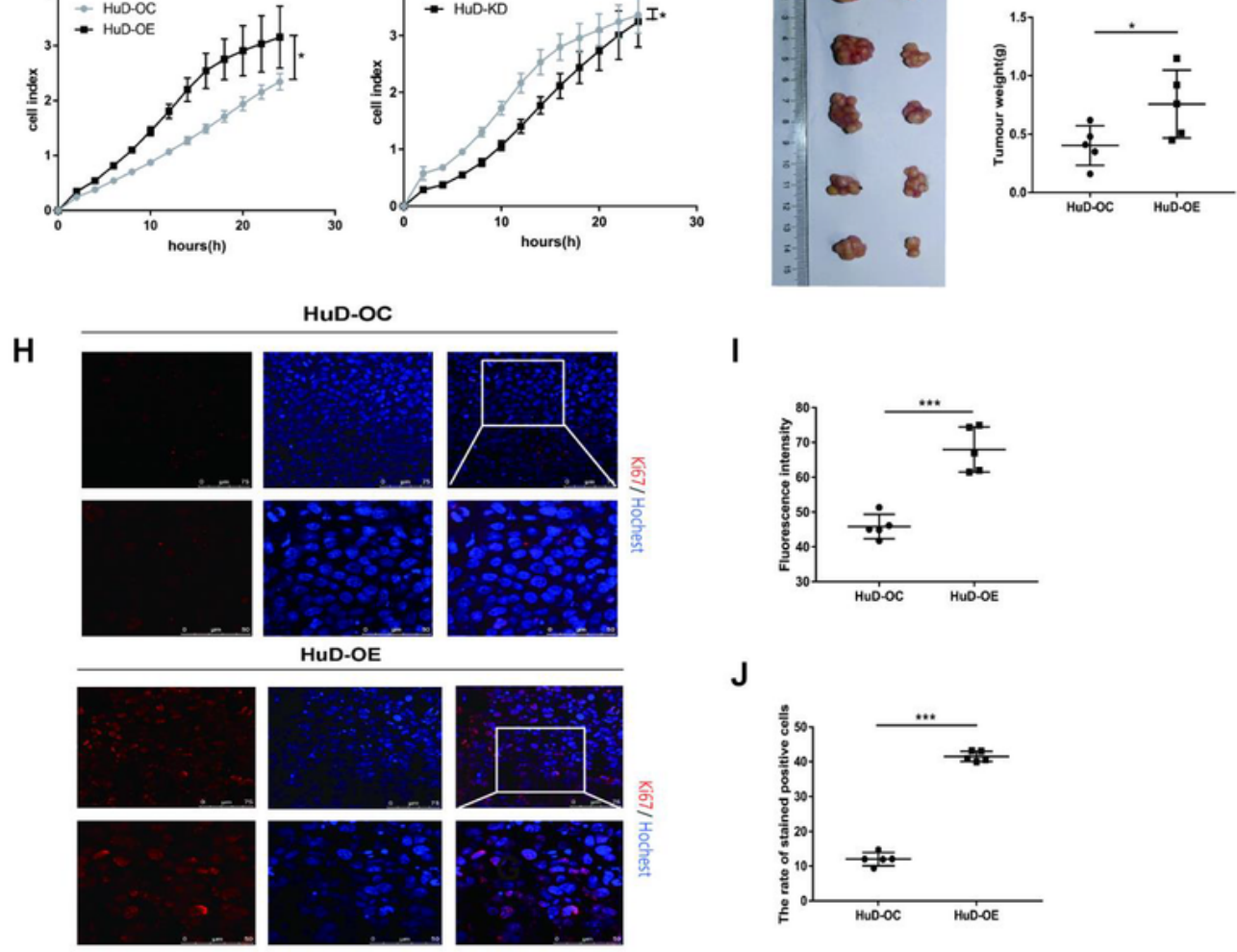

I

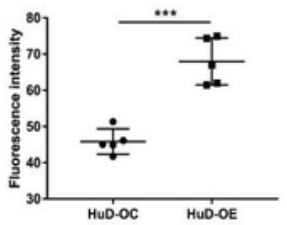

J

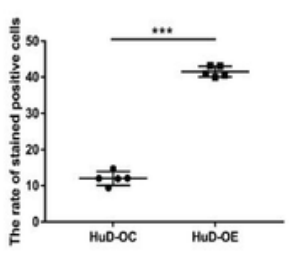

\section{Figure 1}

HuD boosts migration, invasion and cell proliferation of SCLC in vitro and in vivo. A, HuD expression in SCLC and normal lung tissues were detected by Immunohistochemical analysis. B and C, Migratory or invasion capacity of $\mathrm{H} 446$ cells with HuD overexpression or knockdown was measured by Transwell assays. Three independent experiments were performed, and data are presented as mean \pm SD. D and E, RTCA assays revealed the cell proliferation of HuD-OE or HuD-KD H446 cells and their control cells. F, 
Colony formation abilities of HuD-OE or HuD-KD H446 cells were detected by colony formation assay. The number of colonies was calculated and plotted on a histogram. G, The HuD stably expressing group or the negative control were used for tumorigenesis assay. Tumor weighs and volumes were measured. $\mathrm{H}$, $\mathrm{Ki}-67$ staining showed the proliferation ability of HuD-OC and HuD-OE tumor. I and J, The fluorescence intensity and the rate of stained positive cells were analyzed. ( $\left.{ }^{*}, \mathrm{P}<0.05, * *, P<0.01, * * *, P<0.001\right)$

A
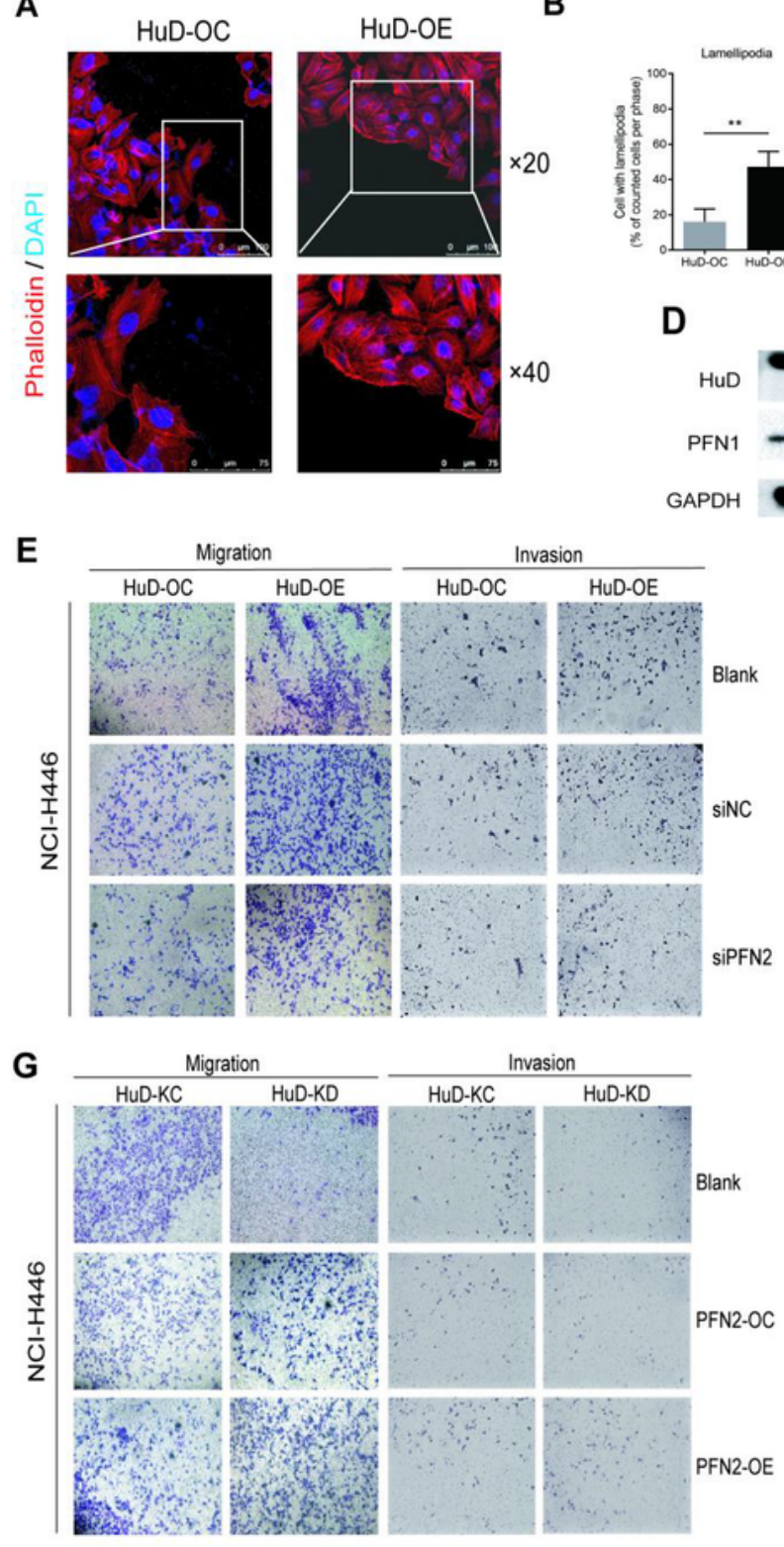

I

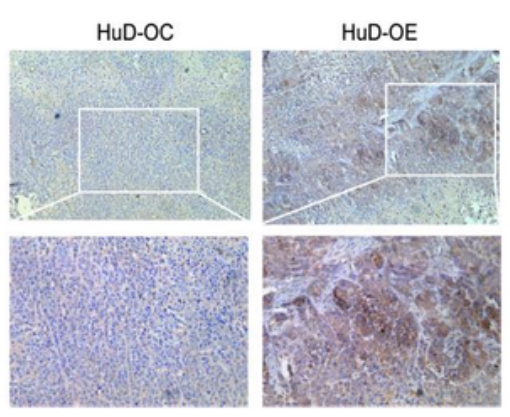

B
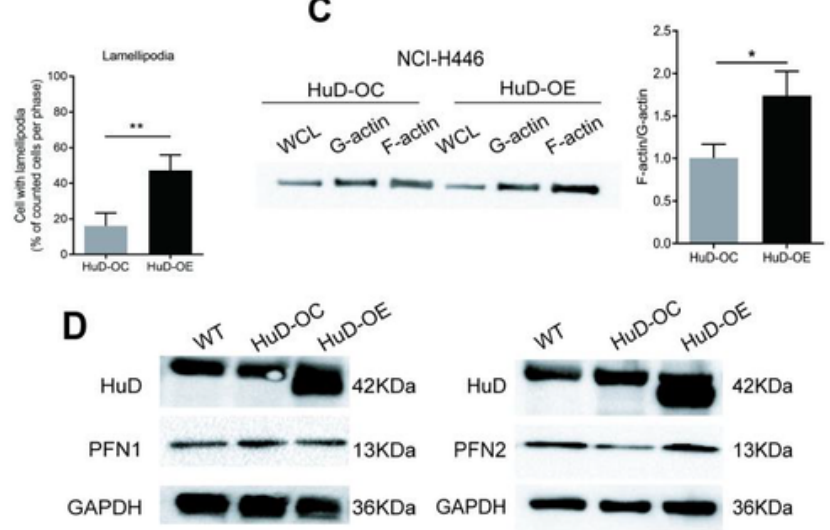

$\mathbf{F}$

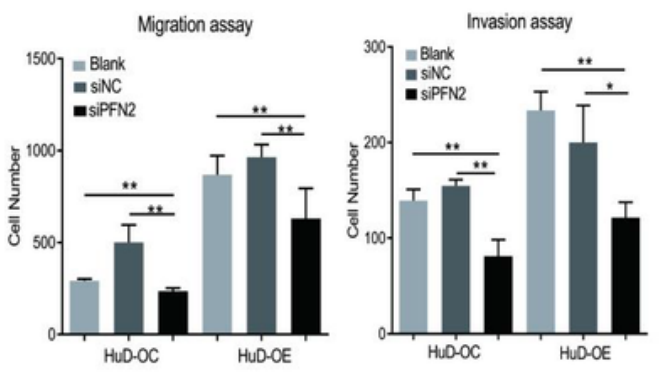

H

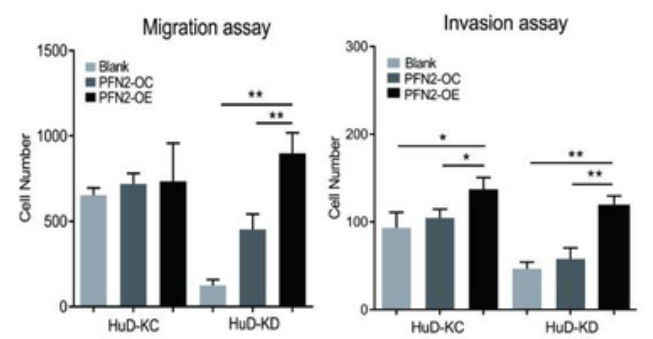

J
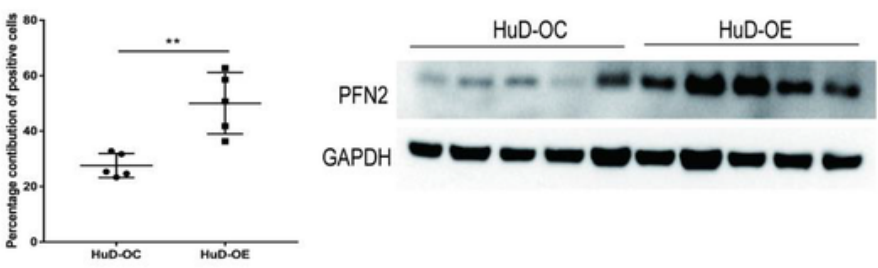

Figure 2 
HuD upregulates the PFN2 expression. A and B, Effect of HuD on lamellipodia formation was showed in $\mathrm{HuD}$ overexpression and negative control $\mathrm{H} 446$ cells. The number of cells with lamellipodia were calculated and plotted on a histogram. C, Cellular fraction analysis was performed to detect the expression of F-actin and G-actin. Histogram showed the ratio of F-actin and G-actin between HuD-OE and HuD-OC groups. D, Western blot analysis showed that PFN2 but not PFN1 was upregulated in HuD$\mathrm{OE} \mathrm{H446}$ cells compared with HuD-OC cells. E and F, Transwell migration assay and invasion assay evaluated the migration and invasion abilities of siPFN2 or siNC on HuD-OE cells. G and H, Transwell assay accessed the migration and invasion abilities of PFN2-OE or PFN2-OC on HuD-KD cells. I, IHC detected the expression level of PFN2 in HuD-OC or HuD-OE tumor tissues in xenograft tumor mice model. J, Western blot showed the expression level of PFN2 in HuD-OC or HuD-OE tumor tissues of mice model. Three independent experiments were performed, and data were presented as mean \pm SD. ${ }^{*}, \mathrm{P}<$ $0.05, * *, P<0.01, * \star *, P<0.001$. 
A

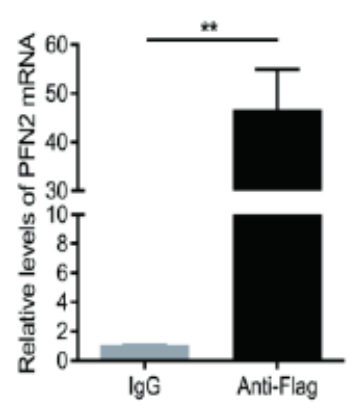

C
D
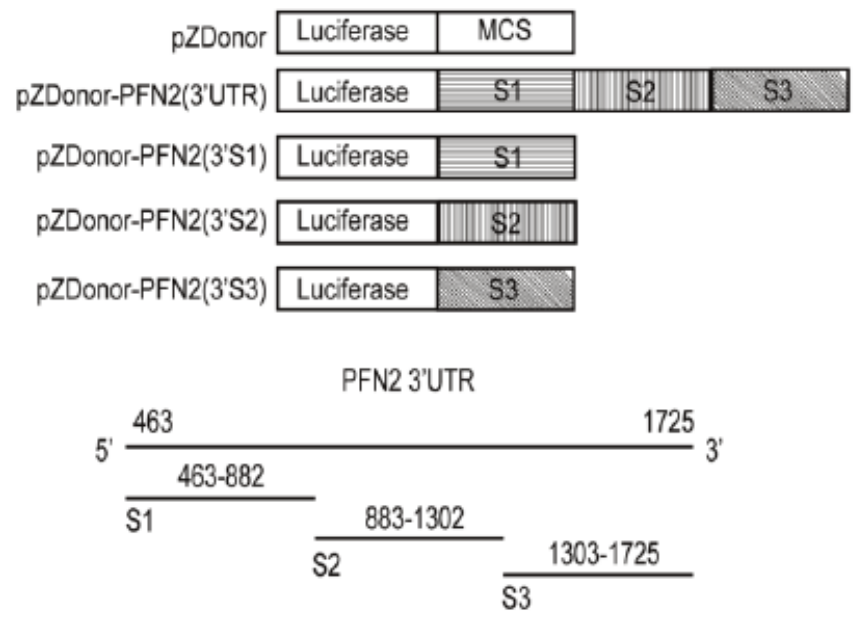

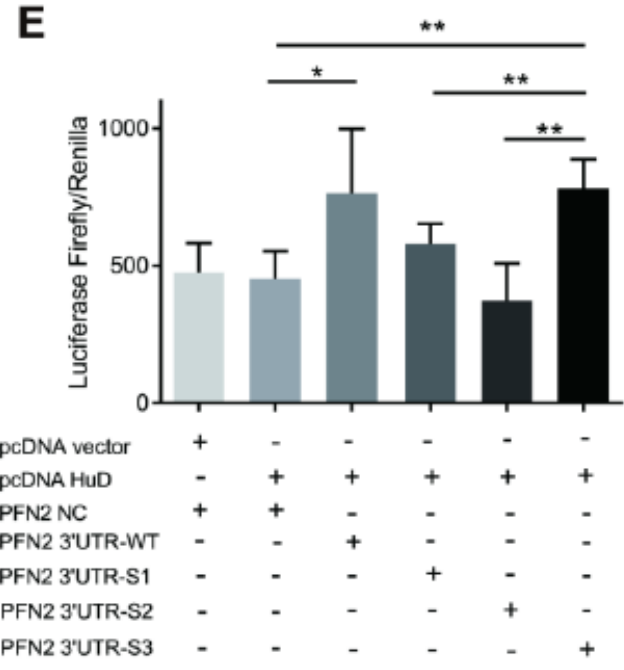

Figure 3

HuD stabilizes PFN2 mRNA by directly binds to the end part of its 3'-UTR. A, RNA immunoprecipitation assay (RIP) indicated that HuD bound to the mRNA of PFN2. B, mRNA stability of PFN2 was measured in H446, HuD-OC and HuD-OE cells. C, Sequence of 3'-UTR of PFN2 mRNA showed the S1-S3 fragments and highlighted the AU-rich elements. D, The full length of 3'-UTR, fragment of S1, S2 or S3 of PFN2 were cloned to the downstream the firefly luciferase reporter plasmids. E, Dual-luciferase reporter assay 
indicated that the full length 3'-UTR and S3 fragment in PFN2 mRNA significantly increased the luciferase activity when HuD was co-expressed in 293T cells. Three independent experiments were performed, and data were presented as mean $\pm \mathrm{SD}$. * $\mathrm{P}<0.05, * *, \mathrm{P}<0.01$.

A

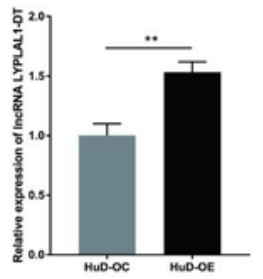

D

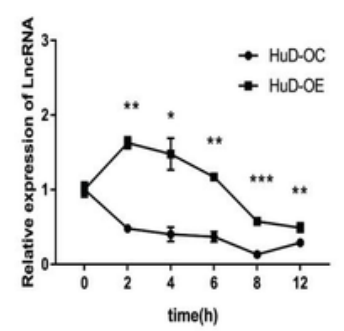

G

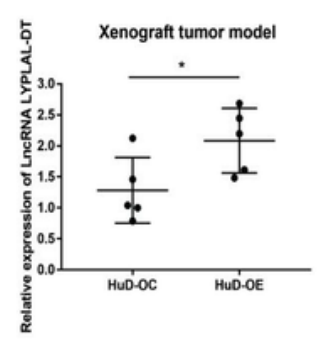

B

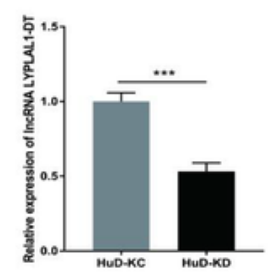

E

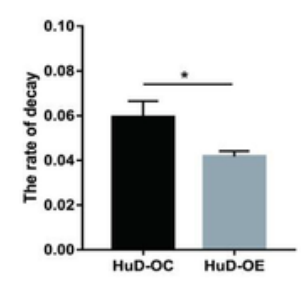

H

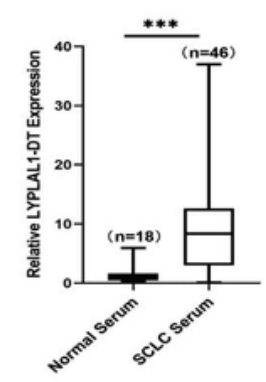

C

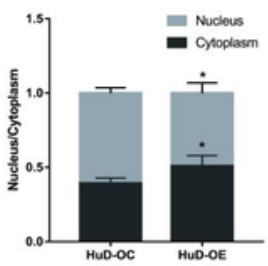

$\mathbf{F}$

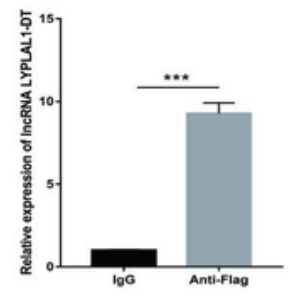

I

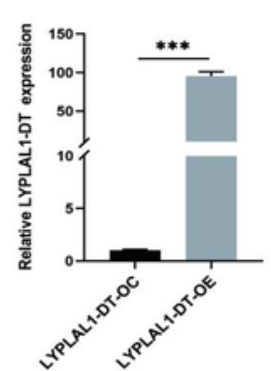

$\mathbf{J}$
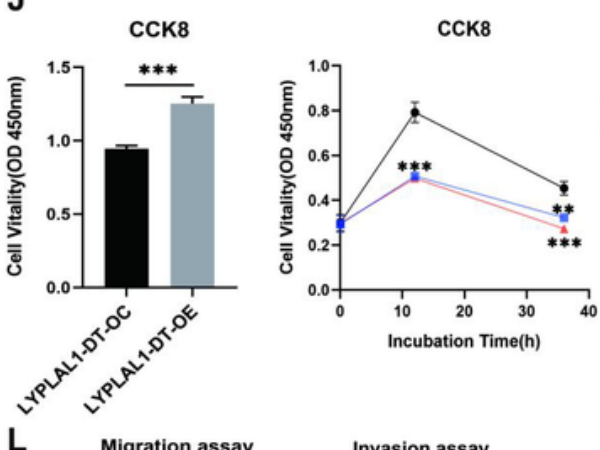

K
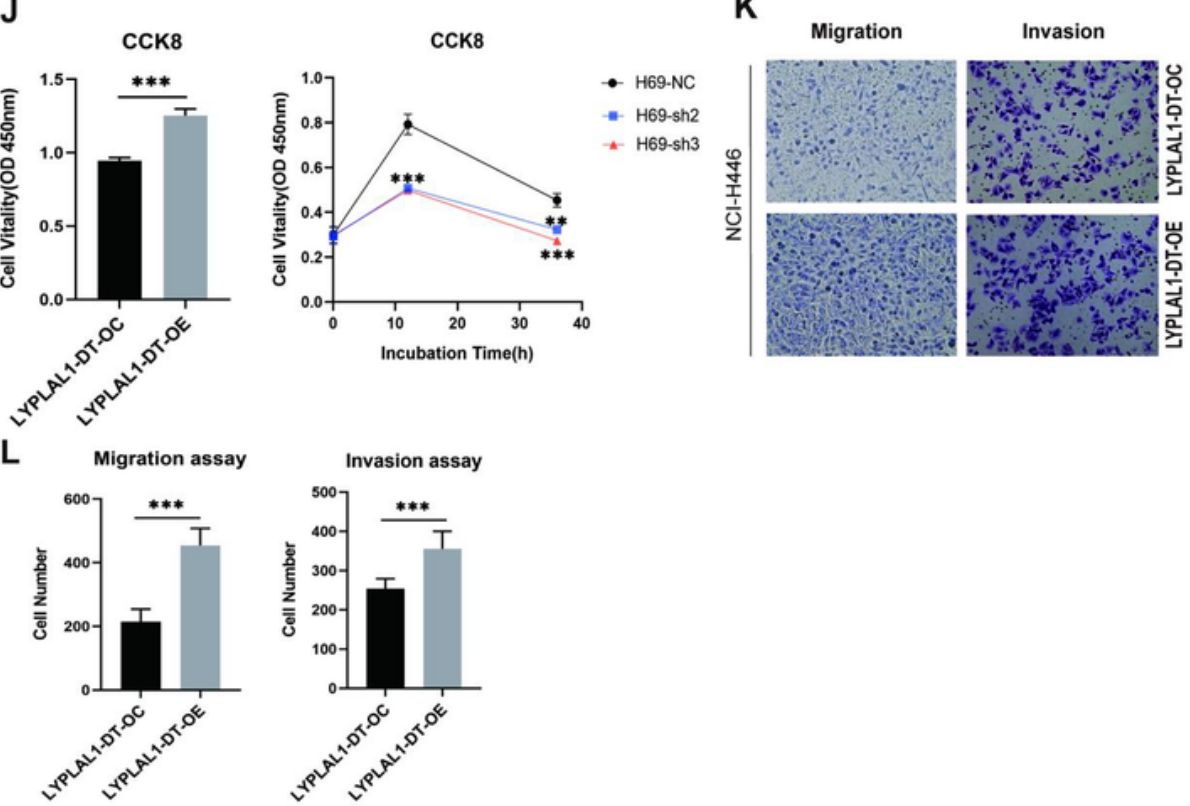

Figure 4

HuD stabilizes LYPLAL1-DT and induces it translocation, which enhances the proliferation, migration and invasion of SCLC cells. A and B, RT-PCR was used to compare the expression level of LYPLAL1-DT in the 
HuD-OE or HuD-KD H446 cells with their control cells. C, Translocation of LYPLAL1-DT after HuD transfection was illustrated by its content ratio of nucleus and cytoplasm. D and E, mRNA stability and decay rate of LYPLAL1-DT was measured in HuD-OC and HuD-OE cells. F, RIP assay by anti-flag antibody or IgG indicated that HuD bound to LYPLAL1-DT. G, RT-PCR exhibited the expression level of LYPLAL1-DT in xenograft tumor samples and control samples. H, RT-qPCR was performed to quantified LYPLAL1-DT level in the serum of SCLC patients $(n=46)$ and normal controls $(n=18)$. I, H446 cells with stably expressing $\mathrm{c}$ or scrambled vector were identified through RT-qPCR. J, CCK-8 assay estimated the effect of overexpressing LYPLAL1-DT on the proliferation of H446 cells or knocking-down LYPLAL1-DT on the proliferation of $\mathrm{H} 69$ cells. $\mathrm{K}$ and L, Effect of LYPLAL1-DT on the migration and invasion abilities of SCLC cells. $(*, P<0.05, \star \star, P<0.01, * \star \star, P<0.001)$ 
A

LYPLAL1-DT 5 GCTCAACATCTTTCAAAGGGAT 3 , IIIIIIII

miR-204-5p 3' uccGuatccuacuguUdcccu 5 '

PFN2-WT 5' AGTCATGGGAAGGAGGTGTC 3 ' || ||| ||| || | |

miR-204-5p 3 U UCCGUAUCCUACUGUUUCCCUU

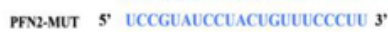

E

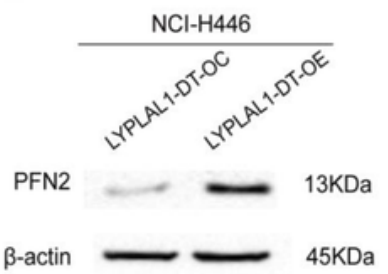

G

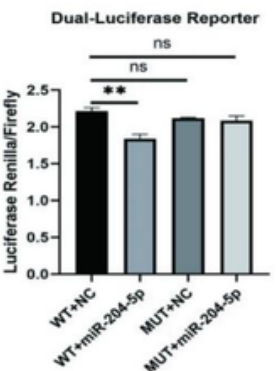

J

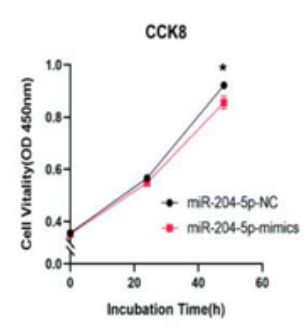

L

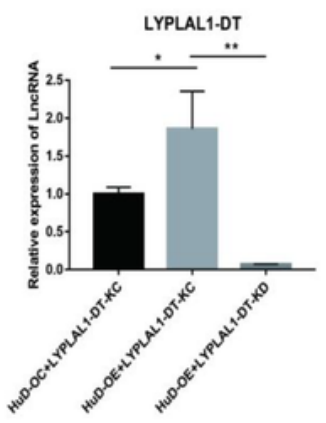

K

H

M
B

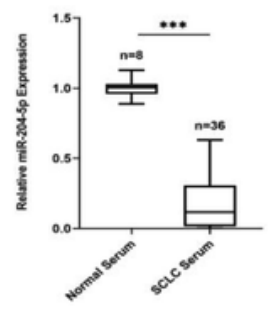

$F$

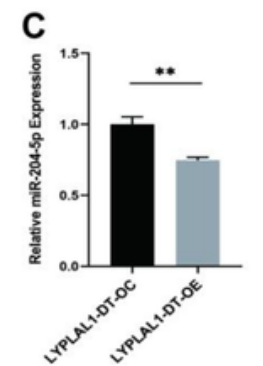

D
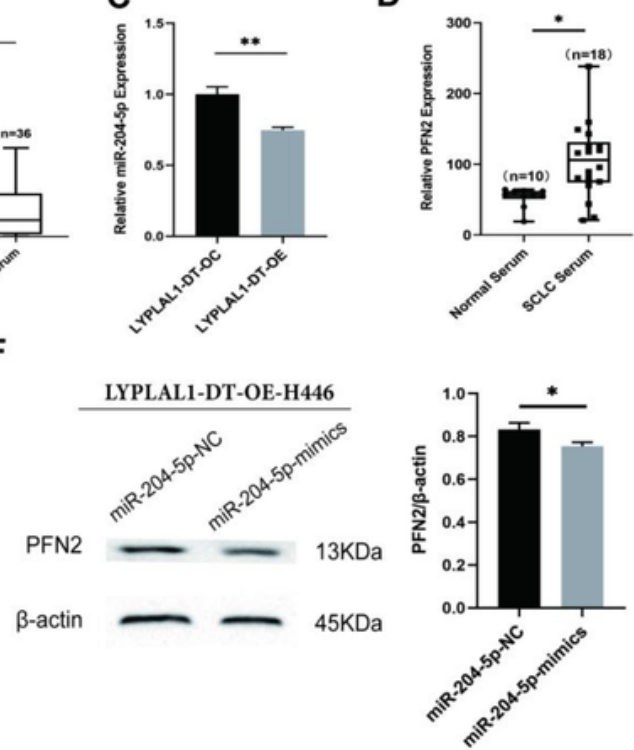

I

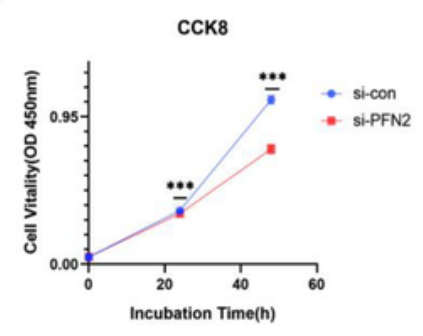

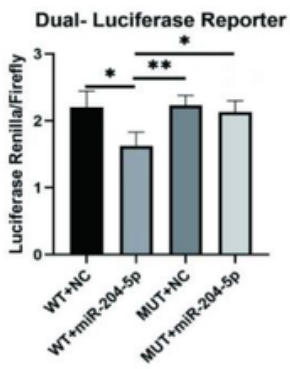
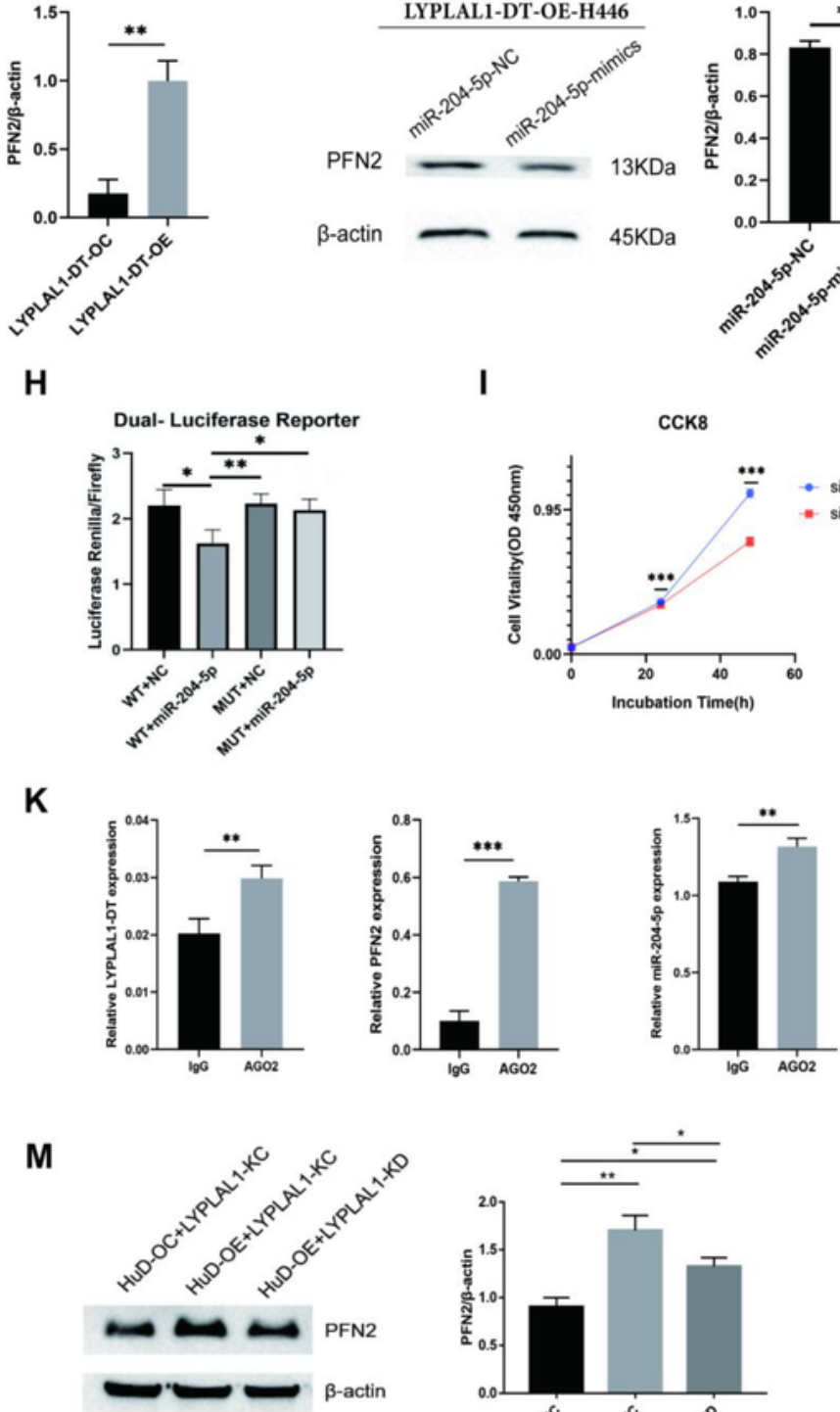

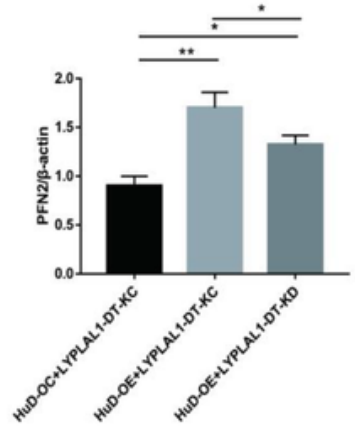

Figure 5

LYPLAL1-DT functions as a decoy for miR-204-5p to increase PFN2 expression. A, The predicted binding site of miR-204-5p in LYPLAL1-DT and PFN2. B, RT-PCR quantified miR-204-5p level in the serum of SCLC patients $(n=36)$ and normal controls $(n=8)$. C, Comparation of miR-204-5p expression level in LYPLAL1DT-OC and LYPLAL1-DT-OE cells. D, ELISA was used to determine the level of PFN2 in the serum of SCLC patients $(n=18)$ and normal controls $(n=10)$. E, The protein level of PFN2 in LYPLAL1-DT-OC and 
LYPLAL1-DT-OE cells. F, Representative image and quantification of the protein level of PFN2 in LYPLAL1DT-OE transfected with miR-204-5p mimic or miR-NC. G, Dual-luciferase reporter assay indicated the luciferase activity in 293T cells co-transfected with WT or mutant LYPLAL1-DT plasmid together with miR-204-5p mimic or miR-NC. H, Dual-luciferase reporter assay showed the luciferase activity in 293T cells co-transfected with WT or mutant PFN2 plasmid together with miR-204-5p mimic or miR-NC. I and J, CCK-8 assay displayed the variation of proliferation of $\mathrm{H} 446$ cells when transfected with si-PFN2 and siCon or miR-204-5p mimic or miR-NC. K, RIP assay showed the binding possibilities of LYPLAL1-DT, PFN2 and miR-204-5p with Ago2 or IgG. L, qPCR assay detected the LYPLAL1-DT level when transfected its KC or KD vector into HuD-OC or HuD-OE-H446 cells. M, Western blot assay detected the alteration of PFN2 in LYPLAL1-DT-KC or LYPLAL1-DT-KD transfected HuD-OE cells (left) and histogram showed the gray value of three independent experiments (right). ( ${ }^{*}, P<0.05, * \star, P<0.01$, ***, $P<0.001$ ) 
A

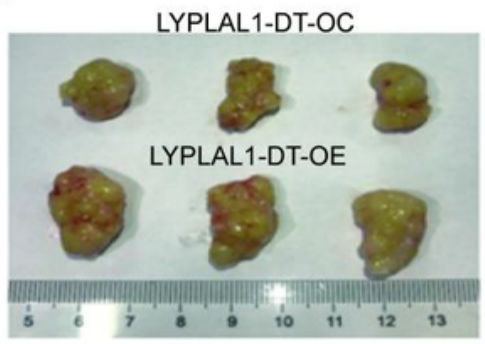

D
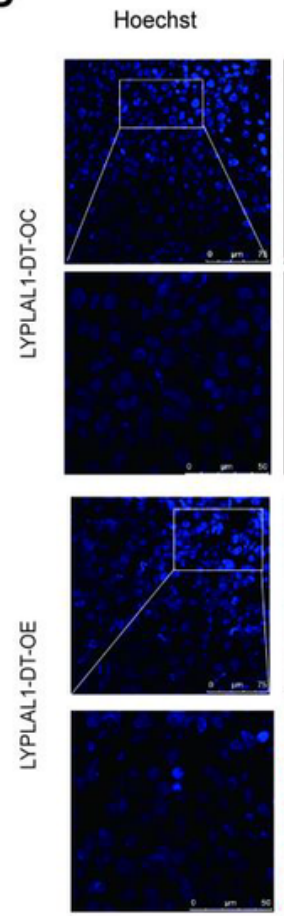

G

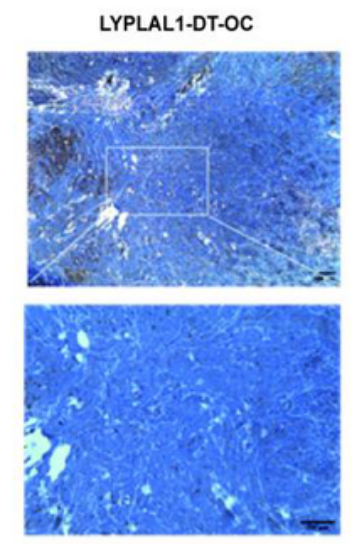

B

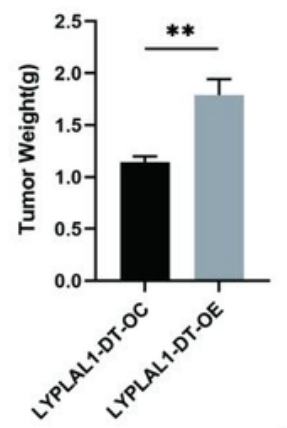

Merge
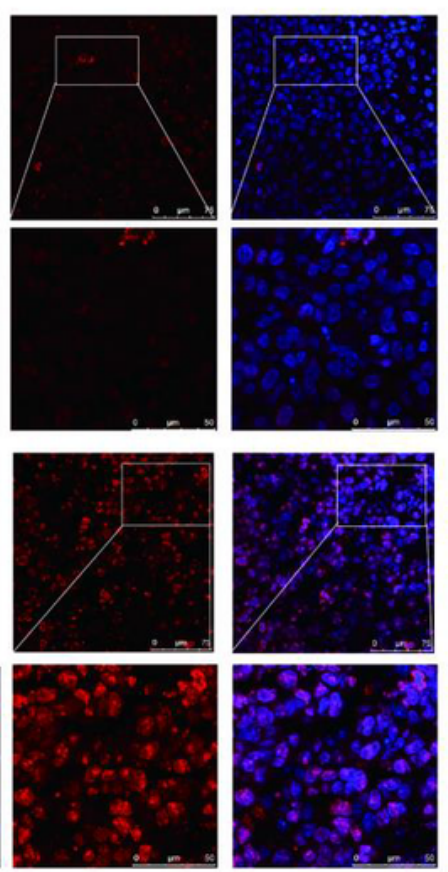

LYPLAL1-DT-OE
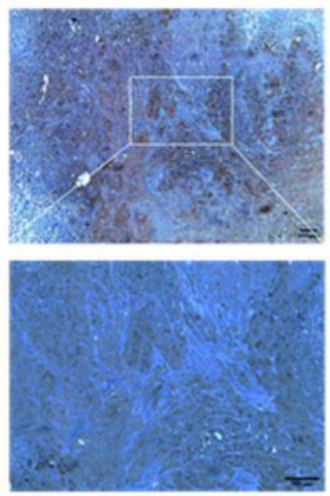

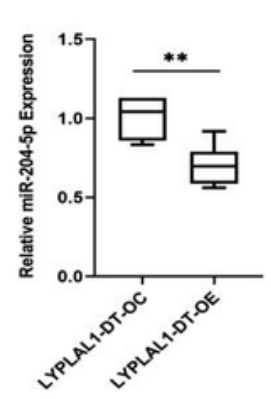

C

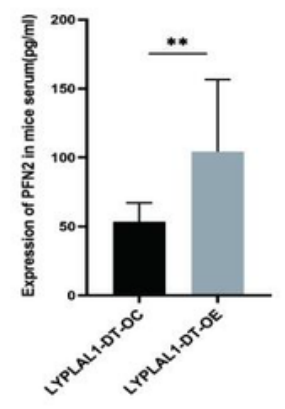

E

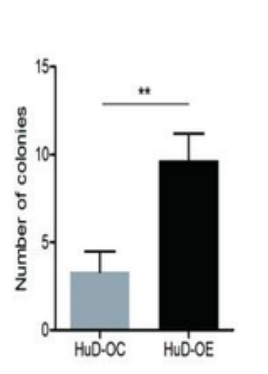

F
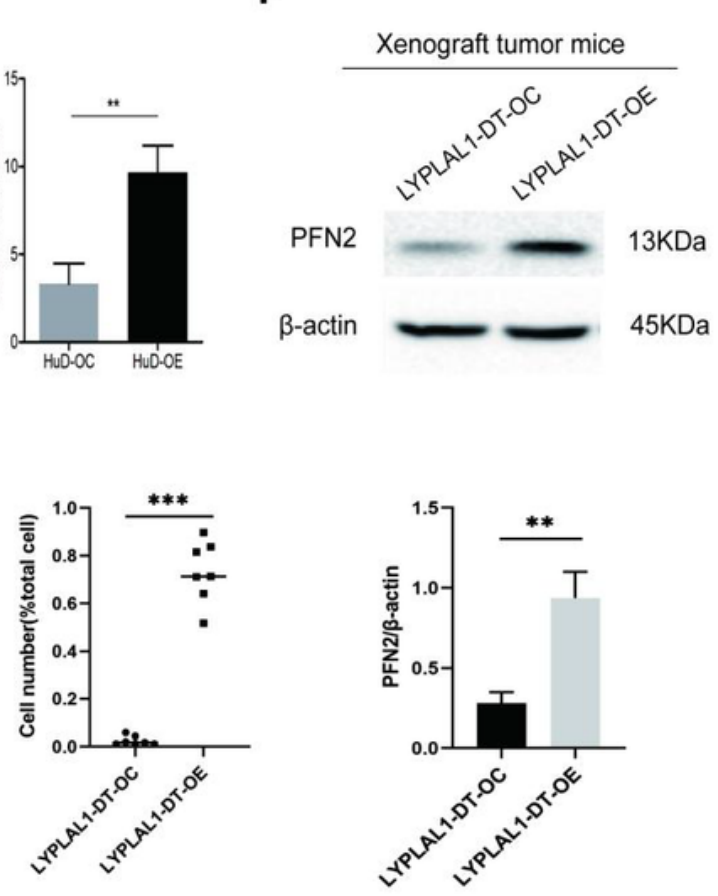

H
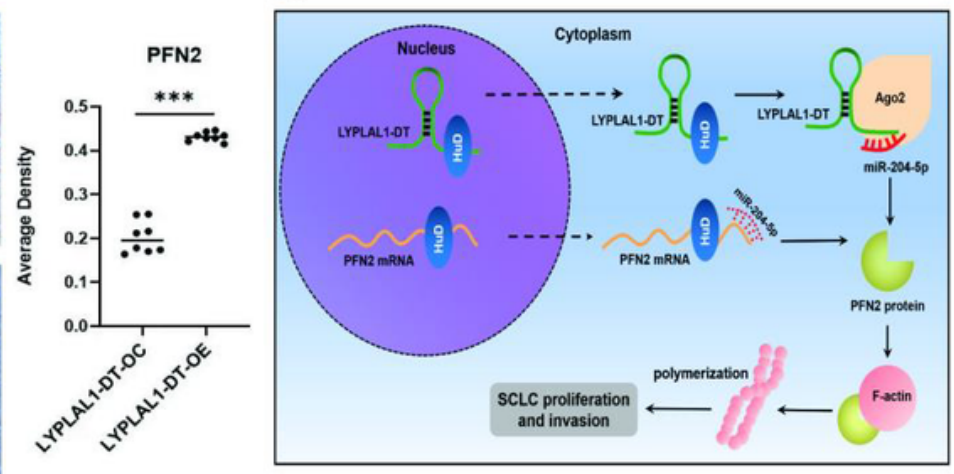

\section{Figure 6}

LYPLAL-DT promotes tumorigenesis of SCLC via miR-204-5p/PFN2 axis in vivo. A, The LYPLAL-DT stably expressing group or the negative control were used -for tumorigenesis assay. The tumor weights and volumes were represented (left) and quantified (right). B, Ki67 immunostaining was performed to evaluate the proliferation ability of LYPLAL1-DT-OE and LYPLAL1-DT-OC cells. The fluorescence intensity (upper) and the rate of stained positive cells (lower) were shown in (C). D, The expression level of miR- 
204-5p in the tumor tissue of xenograft tumor mice. E, ELISA detected the expression level of PFN2 in the serum of xenograft tumor mice. F, Expression levels of PFN2 in the tumor tissue of NOD/SCID mice were accessed by Western blot assay. G, Immunohistochemical staining manifested the PFN2 levels in the tumor tissues of xenograft mice. $\mathrm{H}$, Schematic diagram represented the HuD/ LYPLAL1-DT/miR-2045p/PFN2 axis in modulating SCLC tumorigenesis. $\left({ }^{*}, \mathrm{P}<0.05, * \star, P<0.01, * \star \star, P<0.001\right)$

\section{Supplementary Files}

This is a list of supplementary files associated with this preprint. Click to download.

- Additionalfiles.docx 